\title{
4. Aussprache und Schlußworte
}

\section{Die Bedeutung gliedstaatlichen Verfassungsrechts in der Gegenwart}

Vorsitzender (Tomuschat): Frau Kollegin, meine Herren! Der Ertrag dieses Vormittags muß auf einen jeden Zuhörer eine stimulierende Wirkung gehabt haben. Denn ganz unterschiedlich ist der jeweilige Untersuchungsgegenstand von den drei Referenten bewertet worden. Den vielfältig differenzierten Aussagen von Graf Vitzthum, die auf einen Zustand von bundesstaatlicher Ausgewogenheit, möglicherweise aber auch von Mattigkeit und Farblosigkeit hindeuten, hat Herr Funk ein österreichisches Bild der Substanzentleerung entgegengesetzt, während sich auf der anderen Seite die Schweiz als Ausbund an föderaler Gesundheit darzustellen scheint. Wie kann man diese Diskrepanzen bei drei geographisch so eng zusammenliegenden Staaten erklären? Mit Sicherheit läßt sich sagen, daß die geschichtlichen Traditionen eine ganz wesentliche Rolle spielen. Andere Faktoren und Bestimmungsgründe wird die Diskussion erhellen, die ich nunmehr eröffne. Wie üblich habe ich mich daran gewagt, eine gewisse Gliederung vorzuschlagen, was sicher nicht ausschließen soll und kann, daß sich die Debatte in eine ganz andere Richtung entwickelt.

Isensee: Welche materielle Verfassung hat heute der Freistaat Bayern? Die realistische Antwort: Die materielle Verfassung Bayerns ist das Grundgesetz für die Bundesrepublik Deutschland, ergänzt um die staatsorganisatorischen Teile der bayerischen Landesverfassung; doch auch diese sind, ungeachtet ihrer besonderen Textgestalt, weitgehend angepaßt und harmonisiert dem Grundgesetz.

Cum grano salis läßt sich feststellen: Die Landesverfassungen haben sich in der Staatspraxis auf Organisationsstatute reduziert; und auch in diesem Restbereich ist nur eine konfektionierte, nivellierte Einheitsverfassung für alle Länder verblieben, abgesehen von bestimmten landesspezifischen Modifikationen im Bereich des parlamentarischen Regierungssystems, etwa der Dauer der Legislaturperiode, der Wahl der Regierung, dem Status der Minderheitsregierung, den plebiszitären Möglichkeiten. Die Originalität, die der bayerischen Verfassung von ihrem Text her eigen ist, kommt effektiv kaum zur Geltung. Die Unterschiede der Verfassungstypen sind weithin nivelliert: die Unter- 
schiede zwischen vorgrundgesetzlichen und grundgesetz-synchronen Landesverfassungen, zwischen Voll-, Teil- und Rahmenverfassungen, zwischen kargen Rechtsverfassungen und üppigen Verheißungs- und Programmverfassungen, zwischen Verfassungen mit mehr katholischkonservativer und mehr sozialistischer Programmatik. Die Landesverfassungen kümmern dahin im Schatten der Bundesverfassung. Der Erfolg des Grundgesetzes - Erfolg an normativer Kraft wie an allseitiger Akzeptanz - vollzog sich auf Kosten der Landesverfassungen. Die Frage lautet, ob dieser Preis unvermeidlich ist und ob nicht das Grundgesetz selbst in einer seiner Dimensionen Schaden nimmt.

Der materielle Verfassungswandel und die faktische Verfassungsschrumpfung wirken sich auf die Verfassungstexte nicht aus. Sie haben sich nicht verändert. Förmlich außer Kraft gesetzt sind noch nicht einmal die Vorschriften, die direkt gegen das Grundgesetz oder gegen sonstiges Bundesrecht verstoßen, wie etwa die Regelung der Todesstrafe in Art. 21 der Verfassung des Landes Hessen.

Was sind die Gründe der Bedeutungsminderung? Nur eine untergeordnete Rolle spielt die Homogenitätsklausel des Grundgesetzes, die inhaltliche Vorgaben für die Landesverfassungen enthält. Denn diese Vorgaben richten sich vornehmlich auf die Organisation der Länder. Hier aber ist den Landesverfassungen gerade ein gewisser Selbstand verblieben. - Dagegen geht von den Grundrechten des Grundgesetzes, welche die Staatsgewalt der Länder ebenso wie die des Bundes binden, starker Nivellierungsdruck aus. Sie überlagern die Besonderheiten der Länder in ihren Kultur- und Wirtschaftsverfassungen, ihren Schul- und Staatskirchenartikeln. Die Bundesgrundrechte haben sich in der Interpretation so breit und wirksam entfaltet, daß den Landesgrundrechten wenig Raum für eine gesonderte Entfaltung übrig ist. Es hilft jenen wenig, wenn die Bundesgrundrechte nach Maßgabe des Art. 142 GG nur den Mindeststandard der Freiheit vorgeben sollen, den die Landesgrundrechte überschreiten dürfen. Dem grundrechtlichen Plus zugunsten des einen korrespondiert häufig ein grundrechtliches Minus zu Lasten des anderen, wie es der Fall ist beim hessischen Aussperrungsverbot oder der bayerischen Rundfunkgarantie und (falls hier überhaupt eine Grundrechtsbegünstigung vorliegt) bei den saarländischen wie den hessischen Sozialisierungsartikeln. Derart ambivalente Regelungen der Landesverfassung scheitern am Grundgesetz.

Ich erwarte den Einwand, daß einzelne Länder in den letzten Jahren verfassungspolitische Initiative gerade auf den Gebieten der Grundrechte und der Staatsziele bewiesen hätten mit der Aufnahme des Datenschutzes oder des Umweltschutzes in ihre Verfassungsgesetze, daß sie hier sogar der verfassungspolitischen Entwicklung auf Bundesebene vorausgeeilt seien. Doch die Länder haben verfassungspolitische Aktivität auf Gebieten bekundet, auf denen sie nur geringe 
Gesetzgebungskompetenzen besitzen, auf denen sie also kaum praktische Konsequenzen aus ihren verfassungsgesetzlichen Proklamationen ziehen können und müssen. Es regt sich der Verdacht, daß hier eine Alibi-Aktivität vorliegt, wenn die Verfassungsergänzung sich nicht auf den eigenen Handlungs- und Verantwortungsbereich bezieht. Manche Landesregierung operiert vorsichtiger, wenn die Aufnahme eines Umweltschutz-Artikels in das Grundgesetz im Bundesrat erörtert, als wenn im eigenen Landtag eine entsprechende Ergänzung der Landesverfassung diskutiert wird.

Man würde sich die Sache zu einfach machen, wenn man die geringe Bedeutung der Landesverfassungen damit erklärte, daß sie strukturnotwendig nur eine geringere Bedeutung als die Bundesverfassung besäßen. Denn die Bundesverfassung ist ihrem Wesen nach doppelfunktional: sie ist die Verfassung des Zentralstaates, also des Kompetenzträgers neben den Ländern; sie ist darüber hinaus die gesamtstaatliche Verfassung, die Zentralstaat und Gliedstaaten gemeinsam ist und beide Staatsebenen verklammert.

Die deutschen Landesverfassungen bleiben hinter der Bedeutung zurück, die ihnen an sich die bundesstaatliche Ordnung des Grundgesetzes offen hält. Die Verfassung ist Ausweis der Staatlichkeit. Den Ländern fehlt es an hinreichendem Staatsbewußtsein und damit auch an eigenem Verfassungsbewußtsein. Aufschlußreich ist in diesem Zusammenhang bereits der Wortgebrauch der Staatsrechtslehre. Sie spricht den Ländern „Verfassungsautonomie“ zu, verwendet also eine Vokabel, die an Selbstverwaltung und an Satzungsautonomie erinnert. Nicht zufällig begnügt sich das Land Schleswig-Holstein mit einer „Landessatzung“; dem semantischen Understatement entspricht der Verzicht auf ein eigenes Landesverfassungsgericht, damit der Verzicht auf autochthone Verfassungsinterpretation, und die Verweisung der Verfassungsstreitigkeiten des Landesbereichs an das Bundesverfassungsgericht. Ich frage mich, ob nicht auch die Staatsrechtslehre besser täte, nicht von „Verfassungsautonomie“ der Länder zu reden, sondern von „Verfassungshoheit", ein Wort, das die Staatlichkeit der gliedstaatlichen Verfassunggebung zum Ausdruck brächte.

Das Defizit an Verfassungsbewußtsein, das auf Landesebene zu bemerken ist, besteht auf Bundesebene nicht. Im Gegenteil: Hier ist das Verfassungsbewußtsein vital und machtvoll. Es vermag in gewissem Maße sogar, das notleidende deutsche Staatsbewußtsein zu kompensieren. Der Verfassungspatriotismus bildet eine Art Surrogat des Patriotismus. Doch der Verfassungspatriotismus konzentriert sich auf die demokratischen, die rechtsstaatlichen und die sozialstaatlichen Verfassungselemente. Die Bundesstaatlichkeit bleibt ausgespart.

Auch die Staatsrechtslehre neigt dazu, die Bundesstaatlichkeit zu den minderen Verfassungselementen zu zählen. So figuriert der Be- 
griff des „Verfassungsstaates“ durchwegs als das integrale Ganze der parlamentarischen Demokratie und des sozialen Rechtsstaates - ohne den Bundesstaat. Dieser erscheint denn auch häufig als dem Einheitsstaat unterlegen, als eine Art Kümmerform des modernen Staates. Das antiquierte Ideal monolithischer Geschlossenheit, das vormals gegen Gewaltenteilung und Grundrechte, gegen Parteiendemokratie und Pluralismus ankämpfte, hat zwar für die demokratischen und rechtsstaatlichen Bereiche abgedankt, nicht aber für den föderalen. Dabei wird verkannt, daß der Föderalismus eine Steigerung der verfassungsstaatlichen Idee bedeutet. Er führt zu einer zusätzlichen Dimension der Gewaltenteilung, zu rechtlicher Definition, Bindung und Mäßigung der Staatsgewalt über ein verfassungsrechtliches Kompetenzgefüge. Die staatliche Einheit als solche wird nicht angetastet, wohl aber ausdifferenziert. Der Bundesstaat hat ein besonders hohes $\mathrm{MaB}$ an Verfassungsbedarf. Seine Einheit gründet auf der Verfassung; sie vermag nicht, ohne sie zu bestehen.

Eine außerrechtliche Bedeutung ist der gliedstaatlichen Verfassung geblieben. Sie ist Symbol der Staatlichkeit, Symbol wie Wappen und Fahne. Das ist immerhin etwas. Der Integrationswert darf nicht unterschätzt werden. Aber das ist nicht genug.

Es bestehen weder rechtliche noch politische Notwendigkeiten, daß die Landesverfassungen auf dem niedrigen Bedeutungsniveau verharren, auf dem sie sich heute befinden. In ihnen steckt ein ungenutztes normatives Potential, das dem föderalen Verfassungsstaat vielfältige Lebensimpulse geben könnte: ein Potential an Interpretationsvielfalt, an Innovation, an regionalem, dezentralem Experiment, an kreativer Ergänzung der Bundesverfassung. Selbst dort, wo die Verfassungstexte des Bundes und eines Landes übereinstimmen, bietet sich mehr als die Verdopplung der Rechtsschutzwege. Es verdoppeln sich auch die Interpretationswege, wenn nur genug Interpretationsphantasie und föderales Selbstbewußtsein vorhanden sind. Im föderalen Verfassungsstaat führen viele Wege zur gesamtstaatlichen Einheit, mehr als sie der blockhafte Einheitsstaat kennt. Vielleicht wird diese Staatsrechtslehrertagung dazu beitragen, daß die Chancen, die in den gliedstaatlichen Verfassungen brach liegen, genutzt werden.

Vorsitzender: Das ist die Analyse eines Staatsrechtslehrers aus Nordrhein-Westfalen. Und jetzt Herr Fleiner.

Fleiner: Herr Vorsitzender, meine Damen und Herren, ich bin aufgefordert worden, einige Diskussionspunkte zur rechtsvergleichenden Betrachtungsweise an die drei so hervorragenden Referate anzufügen. Und da es sich um hervorragende Referate handelt, möchte ich nicht nochmals über die Schweiz, die Bundesrepublik oder Österreich spre- 
chen, sondern möchte den rechtsvergleichenden Bogen etwas weiter ausdehnen.

Erster Punkt dazu: Legitimität der Gliedstaatlichkeit oder der gliedstaatlichen Verfassung. Hier haben wir m.E. bereits einige erhebliche Unterschiede feststellen können. Einmal, das kam in einigen Referaten zum Ausdruck, beruht die Legitimität auf der ursprünglichen Staatlichkeit - das gilt sicher für die Schweiz, z.T. für die Bundesrepublik - und auf der Demokratie, was sicher für alle drei Föderativstaaten gilt. Die Legitimität der Gliedstaatlichkeit kann aber auch z.B. in der Krone begründet sein. Ich darf Sie daran erinnern, daß in Kanada wie auch in Australien sowohl der governor wie auch der state-governor der Gliedstaaten von der Krone, d.h. von der englischen Königin, auch heute noch eingesetzt wird und die Legitimität, namentlich der Provinzen in Australien, sich noch aus der Legitimität der englischen Krone ableitet. Wir finden hier also ein ganz anderes Konzept der Legitimität der Gliedstaatlichkeit. Schließlich glaube ich, - das müssen wir föderalistischen Schweizer anerkennen -, gibt es auch eine Legitimität, die sich wahrscheinlich selbst in einem Föderativstaat aus dem Gesamtstaat ableiten läßt. Ich meine beispielsweise etwa in Indien. Namentlich Bundesstaaten, die ihr Bundesparlament mit der uneingeschränkten Souveränität nach dem „Westminster Modell“ ausgestattet haben, gewähren den Gliedstaaten Staatlichkeit, obwohl sich diese nur aus der Souveränität des Gesamtstaates ableiten läßt.

Zweitens: Von Bedeutung für die vergleichende Betrachtungsweise ist die Stellung und die Funktion der Verfassung, die sich m.E. in Kontinentaleuropa - im Gegensatz zu derjenigen der alten common law-Staaten - wesentlich gewandelt hat. Was meine ich damit? Wir haben in europäischen Kontinentalstaaten die Entwicklung zum Monopol des Gesetzgebungsstaates gemacht, eingeleitet durch die Französische Revolution. In den common law-Staaten aber, das gilt m.E. auch für die Vereinigten Staaten, gibt es immer noch zwei wesentliche Rechtsquellen, das positive Gesetz und auf der anderen Seite die Präzedenzfälle der Gerichte, d.h. das common law. Was hat das für Bedeutung für den Föderativstaat? Meines Erachtens hat dieses Gesetzgebungsmonopol wesentlich dazu beigetragen, daß erstens einmal die Verfassungen mehr als Grundgesetze und nicht als Instrument of Government verstanden werden. Zweitens hat dieses Konzept dazu geführt, daß wir den Föderativstaat auf die Hierarchie der Stufenordnung der positiven Rechtserlasse reduzieren, was dann letztlich zum Konzept des Vollzugsföderalismus geführt hat, ein Vollzugsföderalismus, den wir z.B. in den Vereinigten Staaten nicht finden. Dort gibt es im Prinzip zwei voneinander weitgehend unabhängige Rechtskreise und Vollzugsordnungen, nämlich diejenigen des Bundes und diejenigen der entsprechenden Gliedstaaten. 
Das bringt mich auf das dritte Element, das m.E. zu betrachten ist, wenn wir über Föderalismus sprechen: Wir haben Ende des 18. Jahrhunderts zwei Revolutionen gehabt. Die eine, von der wir immer sprechen, die französische, hat zur Einheit und zum Monopol des Gesetzgebungsstaates geführt, die andere, die amerikanische, ist von der Idee getragen worden, das es möglich sein muß, zur Erhaltung der Demokratie, die Demokratie in der Demokratie zu verwirklichen, d.h. wir können eine übergeordnete Demokratie haben, die zum Ziel hat, die gliedstaatliche Demokratie zu erhalten und zu verteidigen. Diese defensive Haltung des Föderalismus der Vereinigten Staaten konnte sich kaum in Europa durchsetzen, es scheint aber, daß die neuen Föderalismusdiskussionen auch in Europa vielleicht der politischen Grundidee zum Durchbruch verhelfen, das sich nämlich durch den Föderalismus allein die Demokratie auf kleinem Raum mit der Demokratie auf groBem Raum in eine Harmonie bringen läßt. Und wenn man von diesem Konzept ausgeht, dann muß man letztlich mit Madison akzeptieren, das es eben eine zweifache Souveränität, eben in diesem Sinne eine geteilte Souveränität gibt. Wir sind getragen vom Gedanken der geistesgeschichtlichen Entwicklung von Hobbes über Rousseau bis zu Kelsen und haben übersehen, das es neben dieser geistesgeschichtlichen Entwicklung eine Entwicklung von Locke über die amerikanische Unabhängigkeitsbewegung zu Madison gibt, die von der Idee getragen ist, das der Staat immer ein Staat ist, der über eine begrenzte und damit eine teilbare Souveränität verfügt.

Schließlich müssen wir für die Zukunft Lösungsmodelle erarbeiten, um den Dualismus, Föderalismus und Rechte, zu bewältigen. Grundsätzlich ermöglicht der Föderalismus den Schutz der Minderheitenrechte auf der Grundlage der territorialen Diversität. Die integrale Gewährleistung der Grundrechte schützt die Minderheiten auf der Grundlage einer zentralistischen, aber pluralistischen gesellschaftlichen Diversität. Dies gilt z.B. für die Vereinigten Staaten, die den gesellschaftlichen Pluralismus nicht durch Föderalismus, sondern nur auf der Basis zentralistischer Gleichbehandlung und Gewährleistung der Freiheit aufrecht erhalten können. Gegenüber diesem ausgeprägten Schutz der individuellen Freiheit stellt sich aber mehr und mehr die Frage, ob der Grundrechtsschutz nicht nur Individuen, sondern auch ganze Gruppen umfassen soll. Muß es neben den Individualrechten nicht auch Gruppenrechte geben, die z.B. kulturelle oder konfessionelle Minderheiten unmittelbar schützen? Wenn wir die Idee der Zielsetzung der amerikanischen Revolution vor Augen halten, daß es letztlich im Föderalismus darum geht, daß wir die kleinen Demokratien durch eine übergeordnete Demokratie schützen können, dann müssen wir natürlich akzeptieren, daß sich Föderalismus, aber auch Gliedstaatlichkeit, mit reiner Souveränitätslehre letztlich kaum völlig erklären lassen. Und so meine 
ich, und damit möchte ich schließen, sollten wir uns auch vom Leitbild der amerikanischen Verfassungsväter tragen lassen, die ihre Arbeit dem folgenden Leitbild unterstellt haben: ,Let experience be our guide because reason might mislead us. "Ich danke Thnen.

Vorsitzender: Vielen Dank Herr Fleiner für die Hinweise auf die Geschichte und die Erfahrungen des ältesten Bundesstaates, der in der Gegenwart noch existiert. Nun Herr Doehring und danach Herr Partsch.

Doehring: Es hat vor 25 Jahren eine Staatsrechtslehrertagung stattgefunden, bei der zu einem ähnlichen Thema einer unserer älteren Kollegen gesagt hat, für ihn seien im Grunde die Länder nur Verwaltungseinheiten. Kurz nach der Bemerkung ist er dann verstorben. (Gelächter) - Aber damals schon stand dem entgegen, daß doch das Bundesverfassungsgericht gesagt hatte, die Länder seien Staaten, echte Staaten mit eigener und richtiger Eigenstaatlichkeit. Das waren die beiden extremen Positionen, vor denen man vor 25 Jahren auch schon stand. Wenn ich dann höre, daß wir hier von der Staatlichkeit der Länder sprechen, hat das immer wieder etwas Gequältes. Es gibt hier offenbar keine Evidenz, denn sonst müßten wir nicht immer wieder beweisen, die Länder haben doch Staatlichkeit; und immer wieder muß betont werden, warum sie diese haben. Offenbar ist das alles nicht selbstverständlich. Das macht nachdenklich, und vor allen Dingen auch hinsichtlich der Terminologie. Können wir denn wirklich sagen, Staatlichkeit des Bundes und Staatlichkeit der Länder sei die gleiche Staatlichkeit? Was ist denn die Staatlichkeit eigentlich? Ich komme auf das internationale Recht noch später in einer Bemerkung zu sprechen. Wenn es dann in den Leitsätzen von Graf Vitzthum heißt, Grundgesetz, Bundesverfassung und Landesverfassung seien jeweils „Teilverfassungen", kommt mir das merkwürdig vor, weil doch das Grundgesetz, wenn man so sagen darf, die Oberverfassung ist und sicherlich mehr Staatlichkeit beinhaltet - nach allen Seiten, nach innen und nach außen - als die Landesverfassungen, die dann vielleicht wirklich „Teilverfassungen" sind. Also, ich meine, man müßte den Begriff der Staatlichkeit zurechtrücken. Man kann nicht für die Kompetenzen der Länder und die Kompetenzen des Bundes den gleichen Begriff der Staatlichkeit verwenden. Das bringt schon terminologische Verwirrung. Denn es ist auch in der Sache nicht das Gleiche. Wir haben im Staat auch nicht nur an die Möglichkeit der Autonomiegewährung zu denken. Die Länder haben ihre Kompetenzen vom Grundgesetz erhalten, andere Träger von Rechten und Pflichten auch - bis hin zur Einzelperson im Hinblick auf die Grundrechte. Die Gemeinden haben „Staatlichkeit“ als Zuständigkeit dort, wo ihnen nichts 
weiteres vorgeschrieben ist. Im Grunde also ist der Unterschied zu den Ländern bezüglich der Autonomie nur ein gradueller. Der einzelne Bürger ist mit seinen Grundrechten auch ausgegrenzt von der Staatsmacht und trotzdem wacht die Staatsmacht darüber, daß er sie nicht mißbraucht; sie können eingeschränkt werden, aber der Bürger hat doch erst einmal diese Freiheit, so wie die Länder ihre Kompetenzfreiheit auch innehaben. Wenn man das Ganze etwas abgerundet betrachtet, dann muß der Begriff der Staatlichkeit auch einmal von auBen gesehen werden. Wir sind doch nicht so introvertiert, daß wir den Staat nur von innen sehen können. Wir haben, aus der Außensicht, die völkerrechtliche Aussage im Report über die Responsibility of States, daß die Subdivisions eines Staates für eigenes Unrecht nicht selbst haften, sondern der Gesamtstaat. Wenn ein Land der Bundesrepublik ein Völkerrechtsdelikt begeht, haftet selbstverständlich der Bund. Das ist die Staatlichkeit, die umfassende. Man kann auch nicht das Vermögen von Bayern auf irgendeiner französischen Bank beschlagnahmen, um Bayern haften zu lassen; man wird deutsches Vermögen beschlagnahmen. Und dann sieht es schon mit der „Staatlichkeit" der Länder ein wenig anders aus. Mich hat übrigens erstaunt, $\mathrm{da} B$ auf die Bundesexekution niemand eingegangen ist. Das Bundesrecht ist nach dem Grundgesetz mit Gewaltmitteln durchsetzbar. Diese Erwägung ist wohl für die „Staatlichkeit“ auch nicht uninteressant. Carl Schmitt hat gesagt, für ihn sei überhaupt das Wesen der Staatlichkeit am jus ad bellum meßbar. Wer kann denn Krieg führen? Ein einzelnes Mitglied eines Bundesstaates kann nicht einmal einen selbständigen Verteidigungskrieg führen. Auch das war ein Kriterium für Staatlichkeit. Wir haben auch sonst noch Gebilde, denen Autonomie garantiert ist. Denken Sie an das Verhältnis von Staat und Kirche. Ulrich Scheuner hat immer die These betont, daß beide Partner seien, der Staat und die Kirche. Aber was bedeutet hier Partner, wenn einer den Bestand des anderen garantiert? Das Grundgesetz garantiert den Bestand der Kirchen. Ohne diese Garantie wären sie vielleicht gar nicht vorhanden. Das Grundgesetz garantiert den Bestand der Länder, und wenn ich die Kompetenzverteilung so sehe, ist das eine Art Delegation, auf die sich die Länder selbstverständlich berufen können. So wie sich das Individuum auf Grundrechte berufen kann, kann sich das Land auf seine Rechte gegenüber dem Bund berufen, aber die Bestandsgarantie kommt von oben. Aller Segen kommt von oben. Danke schön.

Partsch: Graf Vitzthum hat gesagt, Staatlichkeit hätten die Länder, soweit der Bund es ihnen erlaubte. Ich möchte dem die Gegenthese entgegenhalten: Staatlichkeit haben die Länder zunächst nur, wenn sie sie überhaupt wollen. Wie kann man denn von Staatlichkeit reden, 
wenn man das Bewußtsein, ein Staat zu sein, überhaupt beiseite läßt? Als die Landessatzung von Schleswig-Holstein verabschiedet wurde, hat der damalige Justizminister Katz, später Vizepräsident des Bundesverfassungsgerichts, gesagt: $\mathrm{Ob}$ das, was wir hier organisieren, ein Staat ist, diese Frage wollen wir den Professoren überlassen. Jedenfalls aber wollen wir durch unsere Terminologie in keiner Weise dieser Diskussion vorgreifen.

Ich lebe in einem Land, welches sehr zufällig entstanden ist. Das Gebiet von Rheinland-Pfalz war das Land mit den schlechten Kasernen, welches deswegen gut genug war, den Franzosen als Besatzungszone überlassen zu werden. Wenn ich heute in Ingelheim jemanden frage, in welchem Land er lebt, dann ist die selbstverständliche Antwort: „Mir sind Hesse“, weil die Erinnerung an das Großherzogtum Hessen viel stärker ist als das Bewußtsein, in Rheinland-Pfalz zu leben. Ich will damit nicht behaupten, das Bewußtsein alleine schaffe schon die Staatlichkeit; denn das Bewußtsein kann vorhanden sein, und es kann dennoch verhindert werden, daß dieses Bewußtsein sich durchsetzt. Wir haben schon einige rechtsvergleichende Ausführungen gehört, aber ich möchte hier an ein Land anknüpfen, das uns viel näher liegt als Indien - gleich um die Ecke: die Tschechoslowakei ist ein Bundesstaat oder nennt sich so - einzige Frucht des Prager Frühlings. Die beiden Länder Tschechei und Slowakei haben keine Verfassung. Es ist auch dem vorgebeugt, daß die Slowaken einen eigenen Willen betätigen können, indem nämlich die slowakische kommunistische Partei den Weisungen der Zentralpartei der Tschechoslowakei unterworfen ist und indem die Mitglieder des Parteiausschusses der slowakischen kommunistischen Partei gleichzeitig Mitglieder des slowakischen Landesparlaments sind. Ist das ein Bundesstaat? Graf Vitzthum wird wahrscheinlich sagen: nein, obwohl es auf die rein formale Frage nach der Existenz einer Landesverfassung ja wohl nicht ankommen darf, sondern auf die Autonomie der Willensbildung. Beides muß zusammenkommen. Wo das Staatsbewußtsein fehlt, ist auch ein autonomes Gebilde kein Staat.

Vorsitzender: Vielen Dank, Herr Partsch. Ich weiß nicht, ob ein Rheinland-Pfälzer wegen des Quereinstiegs ein Bekenntnis zur Staatlichkeit von Rheinland-Pfalz ablegen will. Dies scheint nicht der Fall zu sein. Dann kommt Herr Öhlinger.

Öhlinger: Ich spreche primär zur Staatlichkeit der österreichischen Länder, möchte aber doch gewissermaßen mit dem genius loci beginnen und bitte Lokalhistoriker um Verzeihung. Als das Bistum Passau vor knapp 200 Jahren säkularisiert wurde, war es meines Wissens Wunsch der Passauer, zu Österreich zu kommen. Wäre das geschehen, 
so wäre Passau heute wahrscheinlich ein Land - ein selbständiges Land, wie es im Art. 2 unserer Bundesverfassung heißt - des Bundesstaates Österreich. Das kann ein wenig die mangelnde historische Substanz einer Staatlichkeit der österreichischen Bundesländer illustrieren. So wie wahrscheinlich manche von Ihnen die Idee eines „Staates" Passau etwas befremdlich finden, so würde wohl der Großteil der Österreicher die Idee eines „Staates" Salzburg, eines „Staates“ Burgenland kaum verstehen. Das Bewußtsein einer Staatlichkeit ist in den österreichischen Ländern kaum vorhanden. Das läßt sich historisch belegen, etwa in Protokollen auch der Landtage aus den Jahren 1918/19. Damals lautete die zentrale Frage: Soll Österreich ein Bundesstaat oder ein Einheitsstaat werden? Einem Abgeordneten zum Salzburger Landtag schien die Idee eines Staates Salzburg so absurd, daß er sie geradezu als Argument gegen eine bundesstaatliche Verfassung benutzte. Die Staatlichkeit der österreichischen Länder ist ein Thema, das auch heute wohl nur im Kreise von Öffentlichrechtlern und rechtlich geschulten Landesfunktionären auf Verständnis stößt, aber den meisten Österreichern fremd ist.

Unser österreichischer Kollege Funk hatte es daher mit einem sehr schwierigen Thema zu tun. Pointiert zusammengefaßt, müßte man sagen: das Landesverfassungsrecht hat in Österreich nahezu keine Bedeutung. In diesem „nahezu“ liegt die ganze Möglichkeit eines Referates über unser Thema aus österreichischer Sicht. Darum beneide ich Herrn Funk nicht. Wenn etwa der Eindruck entstanden sein sollte, daß sein Bericht sehr kritisch war und nicht der Realität des österreichischen Bundesstaates entsprach, so würde ich sagen: sein Bericht liegt eher einige Grade über dieser Realität, gewiß aber nicht unter dieser Realität.

$\mathrm{Daß}$ das Landesverfassungsrecht juristisch geringe Bedeutung hat, läßt sich auch statistisch belegen. Aus der immerhin bis zum Jahre 1920 zurückreichenden Geschichte der österreichischen Verfassungsgerichtsbarkeit, die eine gesamtstaatliche Verfassungsgerichtsbarkeit ist - der Verfassungsgerichtshof ist auch Verfassungsgericht jedes einzelnen Landes - erinnere ich mich ad hoc nur an drei Fälle, in denen eine Bestimmung des Landesverfassungsrechts entscheidungsrelevant war. Wenn man bedenkt, daß der Verfassungsgerichtshof schon seit längerer Zeit pro Jahr an die tausend Fälle zu entscheiden hat, ergeben diese drei Fälle nur einige Promillezahlen. Das ist die juristisch meßbare Bedeutung des Landesverfassungsrechts. Sie liegt, soweit sie gegeben ist, in Wahrheit auf einer anderen Ebene. Gerade die neuere Diskussion um die Reformen und Revisionen der Verfassungen der Länder hat gewiß zu einem gesteigerten Landesbewußtsein beigetragen. Doch auch hier sollten wir uns als Juristen keinen Illusionen hingeben. Die Wiltener Schützen sind für Tirol und der Stefansdom ist für 
Wien sicher von ungleich größerer integrativer Wirkung als die jeweilige Landesverfassung. Trotzdem hat in diesem Punkt das Landesverfassungsrecht einige Bedeutung.

Wenn ich jetzt - das wurde uns ja vom Vorsitzenden erlaubt einen Sprung zu III. machen darf: Die Länder klagen nun immer, daß ihre Verfassungsautonomie so eng begrenzt sei und daher die Bedeutung des Landesverfassungsrechts nicht größer sein könne. Das ist gewiß richtig. Herr Funk hat das treffend dargestellt. Die Schranken, die das Bundesverfassungsrecht den Landesverfassungen setzt, sind sehr groß, und bewirken etwa, das in verfassungsrechtlichen Streitigkeiten, die die materielle Verfassung eines Landes betreffen, viel öfter das Bundesverfassungsrecht als das jeweilige Landesverfassungsrecht entscheidungsrelevant ist. Doch etwas ist merkwürdig, und auch das hat Herr Funk schon erwähnt: Auch innerhalb dieses begrenzten Spielraums haben die Länder ihre Autonomie nicht voll genützt. Offenbar ist für Landespolitiker, auch für die Landesgesetzgeber, das Verfassungsrecht kein besonderes Anliegen. Etwa in der zentralen Frage des Verhältnisses von Parlament und Regierung haben die Länder regelmäßig nur die Neuerungen der Bundesverfassung nachvollzogen. Mir fällt jedenfalls kein Beispiel ein, wonach die Länder im Sinne eines Wettbewerbes moderne Vorstellungen zu diesem Thema gegen den Gehalt der Bundesverfassung eingebracht hätten. Auch die Beispiele der direkten Demokratie und des Briefwahlrechtes sind kein überzeugender Gegeneinwand. Auch in diesen Fällen ging es um Diskus. sionen, die auf Bundesebene initiiert wurden, dort aber parteipolitisch blockiert waren, so daß die Länder, je nach parteipolitischer Dominanz, das, was die jeweilige Partei auf Bundesebene nicht machen konnte, auf Landesebene versuchten. Aber der Anstoß kam von der Bundesebene.

Dennoch, das möchte ich noch sagen, sollte man daraus nicht den Schluß ziehen, der Föderalismus selbst habe in Österreich keine Bedeutung. Der Föderalismus ist hier eine zentrale, auch politisch zentrale, Größe. Er spielt sich nur merkwürdigerweise in der Realität auBerhalb der Kategorien der klassischen Bundesstaatstheorie ab. So haben, um ein Beispiel zu nennen, die Landeshauptleute bedeutsame Positionen mit großem politischen Gewicht, das sie aus ihrer Stellung in den Ländern heraus gewinnen. Das sollte - und das ist ein Appell an mich und meine österreichischen Kollegen - Anlaß zum Uberdenken geben, inwieweit man den österreichischen Bundesstaat nicht besser in anderen als den traditionellen Kategorien der klassischen Bundesstaatslehre zu begreifen hat, um seiner Realität gerecht zu werden.

Vorsitzender: Vielen Dank. Nun hat Herr Grimm das Wort. 
Grimm: Meine Damen und Herren, ich melde mich mit einer kurzen Intervention zu Wort, weil ich befürchte, daß wir die Problematik in einem verkürzten Rahmen diskutieren. Als die Frage nach der Bedeutung der gliedstaatlichen Verfassungen zum Tagungsthema gemacht wurde, war sicherlich primär an ihre juristische Bedeutung gedacht, und fast nur von der juristischen Bedeutung ist in den Referaten und der bisherigen Diskussion die Rede gewesen. Dabei scheint mir aber aus dem Blickfeld zu geraten, daß die juristische Bedeutung von einem außerjuristischen Kontext abhängt, der das Anwendungsfeld und die Entfaltungsmöglichkeiten der Landesverfassungen begrenzt. Dieser außerjuristische Rahmen wird hauptsächlich durch das reale Substrat gezogen, das der Föderalismus heute noch vorfindet. Die Frage danach habe ich in den meisten Referaten und Diskussionsbeiträgen vermißt. Wenn man sie stellt, wird sich zeigen, daß viel mehr als das Vorgetragene von den Landesverfassungen überhaupt nicht zu erwarten ist. Ich will drei Bedingungen nennen, die sich bedeutungsmindernd auswirken. Sie sind an sich jedermann bekannt. Die erste resultiert aus der Problemstruktur und betrifft alle föderalen Staaten mittleren oder kleinen Zuschnitts. Zahlreiche Staatsaufgaben, darunter gerade die modernen wohlfahrtsstaatlichen, sind mittlerweile so beschaffen, daß sie sich in dem kleinräumigen regionalen Rahmen, ja, oft sogar im nationalstaatlichen Rahmen nicht mehr wirksam lösen lassen. Sie wandern dann formell oder informell aus der Zuständigkeit der Gliedstaaten und damit auch aus dem Zugriff der gliedstaatlichen Verfassungen $\mathrm{ab}$. Die beiden anderen Bedingungen treffen zwar nicht für jeden Födealstaat, wohl aber für die Bundesrepublik Deutschland zu. In der Bundesrepublik sind die historischen, ethnischen, kulturellen, religiösen Wurzeln des Föderalismus durch die Folgen des Krieges und die Folgen einer mobilen Industriegesellschaft größtenteils zerstört. Dadurch schwindet aber das natürliche Bedürfnis nach Ausbildung und Wahrung von Verschiedenheit und also die soziale Basis eines kraftvollen Landesverfassungsrechts. Gegenläufige Tendenzen, die in jüngerer Zeit auftauchen und wieder die kleine selbstgenügsame Einheit begünstigen, sind nach meinem Eindruck weder regional radiziert noch politisch motiviert und werden daher kaum der Bedeutung der Landesverfassungen aufhelfen. Drittens überlagert in der Bundesrepublik, aber auch in Österreich, die Parteistruktur den Föderalismus; Parteiloyalitäten sind wirksamer als regionale Eigenständigkeiten. Auch dadurch büßen die Landesverfassungen ohne irgendeine Änderung ihres Normenbestands an realer Bedeutung ein. Erst wenn man diese Bedingungen berücksichtigt, kann man sich ein zutreffendes Bild über die rechtliche Bedeutung von Landesverfassungen und ihr Entwicklungspotential verschaffen. Es wird, wie ich annehme, kein allzu optimistisches. 
Vorsitzender: Herr Selmer muß leider noch warten. Es hat sich Herr Maurer zu Wort gemeldet, noch zum Punkt I, und Herr Vitzthum möchte auch noch kurz Stellung nehmen. Dann beginnen wir mit der zweiten Runde.

H.P. Ipsen: Ich würde gern unmittelbar hieran anschließen.

Vorsitzender: Bitte, Herr Ipsen.

H. P. Ipsen: Meine Bemerkung gehört zum Anfang von II, zumal das von Herrn Grimm hervorgehobene Element unter 3) nicht zur Geltung kommt.

Ich vermisse in den Referaten, die von einer gewissen normativen „Sterilität" bestimmt sind, eine Verdeutlichung der Tatsache, daß unser Staat ein Parteienstaat ist und in allen Beziehungen von Parteienstaatlichkeit beherrscht wird. Als allenfalls ,gehobener Positivist“, als den ich mich einschätze, steht mir zur empfehlenswerten Methode kaum zu, in unserem Kreis auch politologisch zu argumentieren. Aber hier war und ist es nötig. Denn für die Unterschiedlichkeit der Landesverfassungen erscheint mir wesentlich, ihre parteipolitischen Strukturierungen, auch ihre Wahlrechts- und Regierungssysteme, ihre Teilhabe an der Willensbildung im Bundesrat zu beachten. Wenn es danach etwa in Schleswig-Holstein möglich ist, daß das Verhalten eines einzigen Minderheiten-Abgeordneten die dortige Regierungsbildung und damit die entscheidende Mehrheitsbildung im Bundesrat verändert, kann diese etwaige Auswirkung der Parteienstruktur nicht unbeachtet bleiben - wobei ich offen lasse, ob ein solcher Abgeordneter sich nicht nur wegen des politischen Taktes, sondern aus einer Verfassungspflicht heraus solcher etwaigen Einflußnahmen auf die Bundespolitik enthalten sollte.

Im übrigen bewirken Einflußmöglichkeiten von im Bund führenden Parteipolitikern auf die Landespolitik, die sie über die jeweiligen Landesvorsitzenden wahrnehmen (wenn sie dies nicht selbst sind, wie wiederum in Schleswig-Holstein), daß die Landespolitik auch von oben und außen gesteuert werden kann. Wenn alljährlich mehrere Landtagswahlen stattfinden, können solche Einflüsse sich vielfach personalpolitisch und in Fragen der Koalitionsbildung mit Rücksicht auf die bundespolitische Situation auswirken.

Derartige Erscheinungen in ihrer Bedeutung für die landespolitischen Lagen sind in den Referaten nicht zur Sprache gekommen.

Vorsitzender: Meine Damen und Herren, man versucht, mir zu signalisieren durch Blickkontakt, daß man jetzt und genau zu diesem Zeitpunkt etwas zu sagen habe, aber ich glaube, wir sollten bei der 
Ordnung bleiben, wie sie nun einmal vermerkt ist. Sie kommen alle dran. Es scheint so zu sein, daß wir jetzt wirklich den Kern der Sache betrachten. Nun zunächst Herr Maurer.

Maurer: Es ist mehrfach die Frage gestellt worden, ob die Bundesländer Staaten sind oder nicht. Das hängt davon $\mathrm{ab}$, was man überhaupt unter einem Staat versteht. Das Problem ist, daß wir erhebliche Schwierigkeiten haben, den "Staat" zu bestimmen. Wir stehen im Staatsrecht vor der gleichen crux wie im Verwaltungsrecht. Wir haben zwar ein ausgefeiltes Verwaltungsrecht, kommen aber in Verlegenheit, wenn es darum geht, den Gegenstand des Verwaltungsrechts, die Verwaltung, zu definieren. Ähnlich liegt es offenbar im Staatsrecht.

Es gibt bekanntlich eine Reihe von Kriterien, die in der Diskussion um den Staatsbegriff angeführt werden, etwa die Souveränität, die Staatsgewalt, die Integration, das Staatsbewußtsein, die Rechtsordnung usw. Sie ermöglichen jedoch allenfalls Annäherungen, keine exakte Bestimmung des Staates. Herr Schmid hat zu Recht betont, daß die Souveränität heute nicht mehr geeignet ist, die Staatlichkeit festzumachen; sie ist in unserer Staatenwelt mit vielfältigen internationalen Verpflichtungen und Abhängigkeiten mehr als fraglich, jedenfalls nicht mehr im traditionellen Sinne zur begrifflichen Abgrenzung einsetzbar. Aber selbst wenn man sich über einen Begriff des Staates verständigen könnte, bliebe zweifelhaft, ob er im konkreten Fall weiterhilft und zu einer überzeugenden Lösung führt.

Die andere Methode ist, daß man nicht deduktiv, sondern induktiv vorgeht, daß man auf die Feststellung eines vorgegebenen Staatsbegriffs verzichtet und statt dessen bestimmte, für den Staat typische Merkmale entwickelt. An diesen Merkmalen wäre dann zu prüfen, ob den Ländern der Charakter von Staaten zukommt. Ein wesentliches Merkmal ist m.E. die Gesetzgebung. Gerade in dieser Hinsicht bleibt den Ländern jedoch wenig. Die Gesetzgebungskompetenzen der Länder waren schon von Anfang an eng begrenzt. Sie sind im Laufe der Zeit durch die Praxis und durch Verfassungsänderungen noch weiter eingeengt worden. Die korrespondierende Erweiterung der Zustimmungsbefugnis des Bundesrates bringt keinen vollen Ausgleich. $\mathrm{Zu}$ dem sind die Gewinner nicht die Landesparlamente, sondern die Landesregierungen, und auch sie nicht durchweg, sondern wegen des im Bundesrat herrschenden Majoritätsprinzips nur ihre (jeweilige) Mehrheit. Eine Mittellösung scheint die Rahmengesetzgebung des Bundes zu eröffnen, die ebenfalls, vor allem im Bereich des Umweltschutzes, ausgedehnt worden ist, da sie die Gesetzgebung auf Bund und Länder verteilt. Bei näherer Betrachtung zeigt sich jedoch, daß auch insoweit die Länder im Hintertreffen sind. Wenn der Bund ein Rahmengesetz erläßt, dann bedeutet das, daß er die politische Konzeption entwickelt 
und damit die eigentlichen gesetzgeberischen Entscheidungen trifft. Der Landesgesetzgeber kann nur noch ausfüllende Detailregelungen erlassen, nicht viel anders als der Rechtsverordnungsgeber, der gesetzlich zum Erlaß von Ausführungsbestimmungen ermächtigt wird.

Aber selbst dort, wo der Bundesgesetzgeber nicht eingreifen darf und auch nicht eingreift, kommt es zu Beschränkungen des Landesgesetzgebers. Das Staatskirchenrecht, das unbestritten eine Domäne der Länder ist, wird zwar nicht durch den Bundesgesetzgeber, aber durch die Rechtsprechung des Bundesverfassungsgerichts weitgehend determiniert. Das Bundesverfassungsgericht hat in einer Reihe von Judikaten aufgrund der Art. 4 GG und Art. 140 GG in Verbindung mit Art. 137 WRV die Grundlinien des Staatskirchenrechts ausgezogen und zahlreiche staatskirchenrechtliche Einzelfragen entschieden. Die Landesgesetze und die landesgesetzlich sanktionierten Staatskirchenverträge spielen gegenüber der dominierenden Rechtsprechung des Bundesverfassungsgerichts nur eine untergeordnete Rolle.

Die Gesetzgebung ist freilich nur ein Aspekt unter anderen. Die Entwicklung drängt auf eine bundeseinheitliche und damit bundesrechtliche Regelung. Es sei nur auf das Staatshaftungsrecht verwiesen, das allerdings derzeit rechtlich nicht vom Bund und tatsächlich nicht von den Ländern, also überhaupt nicht geregelt werden kann. In anderen Bereichen, vor allem im Bereich der Exekutive, zeigen sich dagegen wieder mehr ,staatskonstituierende“ Momente. Andererseits fragt es sich, ob der Bund alle Essentialia der Staatlichkeit erfüllt. Vieles spricht dafür, daß beide - Bund und Länder - zusammen den „Staat" ausmachen.

Vorsitzender: Vielen Dank. Nun hat Graf Vitzthum das Wort.

Graf Vitzthum: Ein Zwischenruf nur zu den Stellungnahmen der Herren Ipsen und Grimm. Ohne mich als Meister der Realanalyse aufspielen zu wollen - - es ist überaus wichtig, daß wir bei unserer jetzigen Debatte von vornherein die Realität, das heutige Sein des Bundesstaats ganz ins Auge fassen; ich habe einiges dazu im Referat bereits anzudeuten versucht. Meines Erachtens ist die Welle, die scheinbar eindeutig, dauerhaft und irreversibel immer nur in Richtung auf gröBere Einheitlichkeit und stärkere Unitarisierung läuft, an ein Ende, ja bereits ans Kippen gekommen ist. Dadurch, daß Fragen des Vollzugs wie der Kultur, der Ausbildung, der regionalen Wirtschaftsstruktur usw. so wichtig geworden sind, befinden wir uns mittlerweile in einer Bewegung, in der differenzierteres, stärker regionalbezogenes staatliches Agieren und Regieren wesentlich wird. Differenzierung, Nähe, Eigenständigkeit - - dies alles erhält nun einen positiveren Akzent. Wir müssen diesen neuen empirischen Befund in unserer Debatte über 
die verfassungsrechtliche Funktion und Legitimation des Föderalismus stärker berücksichtigen.

\section{Vorsitzender: Vielen Dank, Graf Vitzthum. Nun Herr Selmer.}

Selmer: Ich bin noch nicht sicher, ob der Beitrag von Herrn Ipsen eine Hamburgensie war, eine halbe vielleicht. Mein Beitrag ist gewiß eine. Sie knüpft an Graf Vitzthum an - an Ihre These 4.5. Im Verlaufe dieser These haben Sie auch den Satz aufgestellt, es gäbe keinen Grundsatz landesverfassungsfreundlicher Auslegung von Bundesrecht. Das ist gewiß richtig. Es gibt andererseits aber wohl auch keinen allgemeinen Grundsatz bundesfreundlicher oder bundesrechtskonformer Auslegung, Ausfüllung oder gar Modifizierung des Landesverfassungsrechts. Ein Gegenbeispiel, daß man die Sache auch anders sehen kann, hat leider vor einiger Zeit das Hamburgische Verfassungsgericht geliefert und damit zugleich den Beweis dafür angetreten, daß das Landesverfassungsrecht gelegentlich gegen seine eigenen Freunde geschützt werden muß, Das Hamburgische Verfassungsgericht hat es unternommen, den Grundsatz des bundesfreundlichen Verhaltens zur Aushebelung des Landesverfassungsrechts (Art. 72 I HVerf.) heranzuziehen. Es ging dort um die Einführung des Nettokreditprinzips anstelle des in Hamburg in der Verfassung verankerten Bruttoprinzips durch einfaches Hamburgisches Haushaltsrecht. Das Haushaltsgrundsätzegesetz (§ 12 I 2) stellt in das Ermessen des einfachen Gesetzgebers, welches Prinzip einzuführen ist - das Bruttoprinzip oder das Nettoprinzip. Das Hamburgische Verfassungsgericht registrierte das wohl, registrierte und anerkannte auch, daß die Hamburgische Verfassungsrechtslage damit eine nach Bundesrecht an sich mögliche Entscheidung getroffen hat. Gleichwohl stellte sich das Gericht auf den Standpunkt, mit Hilfe des Grundsatzes bundesfreundlichen Verhaltens sei die entsprechende Vorschrift der Hamburgischen Verfassung im Sinne der Offenheit gegenüber dem Nettoprinzip auszulegen; damit sei dem einfachen Hamburgischen Gesetzgeber das Recht eingeräumt, das Nettoprinzip einzuführen. Ich halte das auch nach nochmaliger Ubberlegung für unrichtig, zugleich für ein Beispiel dafür, was man mit dem Grundsatz bundesfreundlichen Verhaltens nicht machen sollte. Es ist hinzuzufügen, daß das einzige Mitglied des Hamburgischen Verfassungsgerichts, das unserer Vereinigung angehört, diese Auffassung nicht geteilt hat. Herr Bettermann hat sich vielmehr auf Art. 31 zurückgezogen und ist den immerhin vertretbaren, wenn auch angesichts der Entstehungsgeschichte des \& 12 I 2 HGrG zweifelhaften Weg gegangen, mit Hilfe dieser Bestimmung das Ergebnis ohne den Schnörkel des bundesfreundlichen Verhaltens zu begründen. 
Vorsitzender: Vielen Dank, Herr Selmer. Jetzt Herr Kisker.

Kisker: Herr Vorsitzender, meine Herren, die Begriffe „Staatlichkeit" und „Souveränität", wenn bezogen auf die Länder, sind bundesstaatspolitische Kampfbegriffe. Das wird deutlich, wenn man die Diskussion um „Souveränität" und „Staatlichkeit“ der Glieder eines Bundesstaates in ihrem politisch historischen Kontext sieht. Dies gilt sowohl für die US-amerikanische Debatte in Philadelphia und später wie für die deutsche Diskussion vor und nach der Reichsgründung von 1870. - Die Anerkennung von Länderstaatlichkeit hatte politisch wohl auch eine Beschwichtigungsfunktion. Die depossedierte Fürstenherrlichkeit wurde mit einem Charaktermajor abgefunden. Das ging nur, so hat es Paul Laband gemacht, wenn man im Staatsbegriff das nun wirklich nicht auf die Länder passende Erfordernis der Souveränität (im völkerrechtlichen Sinne) durch das geheimnisvolle Kriterium der Originarität ersetzte. Ich warne davor, diese Debatte losgelöst von ihrem politischen Hintergrund erneut zu führen. Wer sich intensiver mit der Problematik befaßt hat, weiß, daß dabei nicht mehr herauskommt als unendliche Variationen von Begriffsspielereien.

Nun zu unserem Thema: „Bedeutung gliedstaatlicher Verfassungen heute". Die Referenten, insbesondere aber auch Herr Isensee haben letztlich gezeigt, daß es mit dieser Bedeutung nicht so sonderlich weit her ist. Für denjenigen, der Verfassungsautonomie für etwas hält, was wesentlich zu ,der Staatlichkeit" der Länder gehört, klingt das erschreckend und läßt für die Vitalität der Länder und damit der bundesstaatlichen Ordnung fürchten. Dem möchte ich widersprechen. Letzten Endes kommt es doch nicht darauf an, ob die Länder speziell über Verfassungsautonomie im großen Stil verfügen, sondern darauf, wieviel Spielraum ihnen die bundesstaatliche Ordnung insgesamt zur autonomen Gestaltung beläßt. Ob die Länder diesen Spielraum mit Verfassungsnormen oder durch einfaches Gesetz ausfuillen, ist für ihre Vitalität als Glieder des Bundesstaates ziemlich belanglos. Ein funktionsfähiges bundesstaatliches System mit lebenskräftigen, selbstbewußten Ländern wäre theoretisch durchaus auch ohne Verfassungsautonomie der Länder denkbar: Wenn die Bundesverfassung den Ländern etwa aus Gründen bundesstaatlicher Homogenität ihre Verfassungsordnungen vorgeben sollte, bedeutet das ja noch keineswegs, daß sie die Länder generell in die Zwangsjacke bundesstaatlicher Vorgaben steckt. Sie könnte ihnen durchaus die Verfassungsautonomie nehmen, ihnen zugleich aber viel umfassendere Gesetzgebungskompetenzen belassen als dies heute in der Bundesrepublik Deutschland geschieht.

Danach wäre es also ganz abwegig, die auf den ersten Blick hin etwas betrüblichen Antworten auf unsere Frage nach der Bedeutung 
gliedstaatlicher Verfassung als Hinweis auf ein Demontieren bundesstaatlicher Prinzipien zu werten. Derartige Demontagegefahren drohen aus anderer Richtung.

Nun zu Herrn Ipsens Forderung, intensiver die tatsächlichen Voraussetzungen für das Funktionieren einer bundesstaatlichen Ordnung, speziell selbständiger Landesordnungen zu erforschen. Für die Bundesrepublik Deutschland gibt es keine umfassende und systematische Untersuchung, welche z.B. die Potenzen vergleichend analysiert, welche die Länder ins Spiel bringen können oder verläßlich ermittelt, inwieweit sich die Bürger mit jeweils ihrem Land identifizieren („Landesstaatsbewußtsein"). D. J. Elazar hat diese Frage für die US-amerikanischen Einzelstaaten in sehr anregender Weise untersucht. - Es fehlt bei uns auch an einem umfassend begründeten verwaltungswissenschaftlichen Versuch zu klären, was man (um der Entmachtung der Länder entgegenzuwirken) den Ländern an zusätzlichen Kompetenzen überlassen könnte und was ihnen umgekehrt früher oder später um der Funktionsfähigkeit des Gesamtverbandes willen wird entzogen werden müssen. - Angesichts solcher Defizite stimme ich also Herrn Ipsen zu: Wir müssen uns um die tatsächlichen Voraussetzungen für das Funktionieren unserer bundesstaatlichen Ordnung intensiver kümmern, auch wenn dies uns Staatsrechtler im Ergebnis dazu zwingen sollte, diese oder jene liebgewonnene, tradierte Denkfigur beiseitezulegen.

In diesen Zusammenhang gehört auch die, wenn ich das richtig verstanden habe, von Herm Grimm vorgetragene These, in einer modernen Industriegesellschaft wie der unsrigen sei der Trend hin zu mehr Unitarisierung unausweichlich. Das kann wohl so eindeutig nicht sein: In der Schweiz gibt es doch eine moderne Industriegesellschaft und trotzdem leistet man sich dort (prinzipiell unangefochten) eine gliedstaatliche Selbständigkeit, die über die Selbständigkeit unserer Bundesländer weit hinausgeht. Auch was diese sehr wichtige Problematik angeht, müßten wir endlich einmal über das ständige Wiederholen sozialwissenschaftlich nicht abgesicherter Thesen hinauskommen.

Ähnlich ist es mit der von Herrn Ipsen ausdrücklich angesprochenen Problematik des „Parteienbundesstaates“. Wenn man mit diesem Schlagwort einen Bundesstaat meint, der faktisch von zentralistisch organisierten politischen Parteien gesteuert wird, so meine ich: das gibt es in der Bundesrepublik Deutschland nicht. Man darf sich die politischen Parteien nicht als wirklich straff organisierte Blöcke vorstellen, die bundesweit einheitlich auf das Kommando einer Parteizentrale reagieren. Daß dies bei den Unionsparteien (CDU/CSU) nicht klappt, haben wir ja in jüngster Zeit immer wieder den Nachrichten entnehmen können. Aber auch innerhalb der SPD gibt es sehr gewichtige regionale Varianten; so etwa in Hessen den ,linken“ Bezirksverband Hessen-Süd einerseits und den eher ,gemäßigten“ Bezirksver- 
band Hessen-Nord andererseits. - Diese Vielfalt hat ihren Grund auch in der bundesstaatlichen Ordnung. Insoweit kann man von einer Föderalisierung der politischen Parteien sprechen. Es ist also nicht nur so, daß die Bundeszentralen der politischen Parteien in der Regel unitarisch orientiert sind, sondern zugleich bewirkt die föderalistische Organisation des Staates und die an sie angelehnte quasi-föderalistische Organisation der politischen Parteien eine beträchtliche Entmachtung der Parteizentralen. Das ist ein m.E. durchaus positiv zu wertender Prozeß, der die These, in der Bundesrepublik Deutschland werde die föderalistische Vielfalt von unitarisch orientierten Parteien überformt, doch erheblich einschränkt.

Das alles scheinen mir Fragen zu sein, deren Beantwortung für die Erhaltung einer lebensfähigen bundesstaatlichen Ordnung wesentlich bedeutsamer ist, als die Bewahrung einer schon begrifflich fragwürdigen „Landesstaatlichkeit“ oder gar „Landessouveränität“, ja sogar wichtiger als die Erhaltung und der Ausbau von Landesverfassungsautonomie.

Vorsitzender: Vielen Dank, Herr Kisker. In dem Thema steckte offenbar eine gewisse Zweideutigkeit, weil zwar primär von der Bedeutung des Landesverfassungsrechts die Rede, gleichzeitig damit aber auch der Status der Länder selbst angesprochen ist. Somit bewegt sich das Thema zwischen diesen beiden Polen etwa in der Mitte. Nun Herr Stern, bitte.

Stern: Versucht man, Gemeinsames aus den drei Referaten herauszusuchen, so hatte ich den Eindruck, daß wiederum die Grundhaltung überwog, die Landesverfassung und die Landesstaatlichkeit, um beide zusammen zu nehmen, aus ihrem Schattendasein herauszuführen, gewissermaßen die Renaissance, die von einigen von uns bereits mit Büchern und Aufsätzen eingeleitet worden ist, fortzusetzen. Allerdings glaube ich, daß vor allen Dingen in der Diskussion jetzt doch einiges Wasser in diesen Wein geschüttet wurde. Hier möchte ich einige Gegenpositionen setzen; die gute Regie des Vorsitzenden hat mich vielleicht auch deshalb gerade jetzt aufgerufen.

Natürlich ist es wichtig, wenn gefragt wird: Wo ist denn das Staatsbewußtsein in den Ländern? Ich stelle die Frage etwas anders gewendet: Haben die Länder noch politische Eigenständigkeit, haben sie insonderheit die Möglichkeit, verfassungsrechtlich leistungsfähig zu sein? Graf Vitzthum und die anderen Referenten haben mit Recht aufgezeigt, daß beides eingebettet ist in die Bundesverfassung und für die Bundesrepublik Deutschland dazu noch in die supra-nationale Gemeinschaft. Wenn man nun das Popitz'sche Gesetz der Anziehungskraft des größeren „Etats“ heranzieht, dann ist selbstverständlich die 
Diagnose richtig, daß die Bundesverfassung in allen drei Ländern einen Sog auch zur Auszehrung der Landesverfassungen ausgeübt hat. Aber dennoch meine ich, daß skeptische Untertöne aus dieser mehr von oben herrührenden Betrachtung nicht angebracht sind, wenn man die Dinge auch einmal von unten, also von den Gliedstaaten her, betrachtet und fragt: Gibt es nicht doch noch einen spezifisch eigenen Rechtswert der gliedstaatlichen Verfassungen? Daß dieser für die einzelnen Bundesstaaten unterschiedlich ist, liegt einmal an den Grundbefindlichkeiten der drei hier behandelten Länder, aber im Rahmen der Bundesrepublik Deutschland selbstverständlich auch der einzelnen Bundesländer selbst. Wer an den Universitäten von drei deutschen Bundesländern gewirkt hat wie ich - in Bayern, Berlin und Nordrhein-Westfalen -, hat natürlich sehr rasch gespürt, daß hier wesentliche Unterschiede in der Staatskraft bestehen. Stellt man also die Frage, was läßt sich vom gliedstaatlichen Verfassungsrecht als verfassungsrechtliche Kraftfelder aufrechterhalten, dann meine ich, daß von daher, - und das erinnert an das, was der Vorsitzende gesagt hat, es sollte das Thema auch etwas verfassungstheoretisch betrachtet werden - Gewichtungen, Potentiale und Spannungslagen der gliedstaatlichen Verfassungen in sehr unterschiedlicher Weise auftreten.

Zunächst einmal ist es ganz selbstverständlich, daß die Landesverfassungen die Ausformung der Organisation der Eigenstaatlichkeit der Länder vorzunehmen haben. Ich stimme Graf Vitzthum zu, daß Art. 28 I GG nur geringe Schranken zieht; andere Bestimmungen der Bundesverfassung sind in ihren Einwirkungen auch nicht so stark, daß die Länder nicht doch erhebliche Eigenstaatlichkeit entwickeln können.

Das Zweite ist die Vorbild- und Vorreiterfunktion, die einige Landesverfassungen gehabt haben. Das gilt natürlich vor allen Dingen für diejenigen, die bis 1949 ergangen sind. Viele Formulierungen sind aus diesen - besonders im Grundrechtsteil, aber auch anderswo - in das Grundgesetz eingegangen. Gleiches gilt auch, und nicht zuletzt in wichtigen Fällen, für die Rechtsprechung der Landesverfassungsgerichte, die das Bundesverfassungsgericht zumindest im ersten Jahrzehnt deutlich beeinflußt haben. Möglicherweise spielt jetzt auch das Umweltschutzstaatsziel, über das in Kürze von Bundes wegen entschieden werden soll, das in einigen Landesverfassungen bereits enthalten ist, eine Rolle.

Drittens kann man die Komplementärfunktion herausstellen, die im Bereich von Kultur, Erziehung, Bildung und Schule von Bedeutung ist. In diesen Bereichen ist immerhin in den Ländern auch einiges geschehen. So haben sich in Hessen Eltern und Schüler auf die entsprechenden Artikel der Landesverfassung berufen und aus ihnen für sie Günstiges herausgeholt. Nichts anderes gilt für die Privatschulen in 
Nordrhein-Westfalen. Auch hier wurden die entsprechenden Artikel aktiviert; wer sie etwas genauer durchliest, der wird alsbald die Frage stellen müssen: Wie sieht es denn in der Praxis des Schulwesens aus im Verhältnis zu den einschlägigen Bestimmungen der Landesverfassungen? Auch hier ist also noch landesverfassungsrechtlich entwicklungsfähiges Potential vorhanden.

Schließlich ist auch eine gewisse Konkurrenzfunktion zwischen Bundes- und Landesverfassungen zu beachten. Ich habe gerade beispielhaft das Umweltschutzstaatsziel erwähnt, aber auch gewisse Grundrechte sind zu nennen. Art. 4 I der Landesverfassung NW hat ebenso wie die baden-württembergische Verfassung die Grundrechte des Grundgesetzes rezipiert. Was bedeutet dies? Sind das jetzt Grundrechte des Landes? Wie steht es, wenn Grundrechte übereinstimmen, wenn neue Grundrechte hinzukommen - etwa in Nordrhein-Westfalen das Grundrecht des Datenschutzes, Art. 4 II - im Verhältnis zur Grundrechtsrechtsprechung des Bundesverfassungsgerichts, etwa zum Urteil über das informationelle Selbstbestimmungsrecht? Eine Reihe offener Fragen, bei denen Art. 31, 142 GG - jedenfalls in meinen Augen - so einfach die Antwort nicht geben, sondern eine Reihe schwieriger Probleme aufwerfen. Oder wie steht es mit der Kollisionslage bei den Sozialisierungsgrundrechten, die in einzelnen Landesverfassungen enthalten sind, und verschiedenen anderen mit der Bundesverfassung in Widerspruch stehenden Grundrechten? Wie ist es mit den noch offenen Fragen des Staatskirchenrechts?

Der Bereich der Landesverfassungsgerichtsbarkeit darf nicht unerwähnt bleiben: Natürlich ist die Landesverfassungsgerichtsbarkeit in den Sog der Verfassungsgerichtsbarkeit des Bundes geraten. Möglicherweise spielt hier der Art. 100 III GG eine gewisse einschränkende Rolle, der freilich auch anders ausgedeutet werden kann. Ich habe einen diesbezüglichen Versuch an anderer Stelle unternommen. Meine dezidierte Zustimmung gilt der Bemerkung von Graf Vitzthum, ohne eine Verfassungsbeschwerde $\mathrm{zu}$ den Landesverfassungsgerichten ist eine Effektuierung der Landesgrundrechte nicht groß, jedenfalls nicht zureichend. Das sieht man an Bayern und Hessen auf der einen Seite und anderen Ländern, etwa Nordrhein-Westfalen, auf der anderen Seite. Der Art. 4 II der Landesverfassung NW mit dem Datenschutzgrundrecht ist gewiß das wichtigste Beispiel dafür, daß der Bevölkerung durch eine Verfassungsvorschrift etwas gewährt wird, etwas gewährt werden sollte, aber wenn es dann an die Umsetzung geht, nutzt diese Verfassungsvorschrift im verfassungsgerichtlichen Verfahren herzlich wenig. Vielen Dank.

Vorsitzender: Herzlichen Dank. Herr Bachof, bitte. 
Bachof: Graf Vitzthum, Sie haben in Ihrem Leitsatz 4.6 geäußert, die starke Anlehnung der Landesverfassungsgerichte an die Rechtsprechung des Bundesverfassungsgerichts sei nicht unabdingbar. Ich möchte die Gegenthese aufstellen: Sie ist unabdingbar. Sie haben sicher recht, wenn Sie die Dinge allein unter dem Aspekt des Verfassungsrechts betrachten. Aber wenn wir, was auch Herr Grimm getan hat, die Dinge im Blick auf die Verfassungswirklichkeit betrachten, so sieht das anders aus. Herr Stern hat recht, daß die Rechtsprechung des Bundesverfassungsgerichts anfangs sehr stark von derjenigen der zum Teil älteren Landesverfassungsgerichte beeinflußt war. Aber das Verhältnis hat sich seitdem zunehmend umgekehrt. Ich habe das in den 27 Jahren als Landesverfassungsrichter beobachtet, nicht ohne lebhaftes Bedauern. Zwar gibt es zahlreiche Materien, in denen eine Konkurrenz zwischen Bundesverfassungsgericht und Landesverfassungsgerichten kaum auftaucht. Hier bleibt die Bedeutung des Landesverfassungsgerichtes bestehen, denken Sie an das Polizeirecht, das Schulrecht, das Hochschulrecht, vor allem aber an das Gemeindeverfassungsrecht, für welches die Rechtsprechung des Landesverfassungsgerichts von größter Bedeutung wurde, wie wir bei der Kommunalreform gesehen haben. Aber bei allen vor die Landesverfassungsgerichte gebrachten Fragen, mit denen sich schon, unmittelbar oder mittelbar, das Bundesverfassungsgericht befaßt hatte, zeigten die Landesgerichte eine ausgesprochene Scheu, davon abzuweichen. Ja, selbst auf solchen Gebieten wie etwa der Regierungsbildung, dem Wahlrecht, dem Untersuchungsausschußrecht, wo das Grundgesetz nicht einmal mit der betreffenden Landesverfassung übereinstimmende, sondern nur mehr oder minder ähnliche Regelungen enthält: Selbst dort hat man eher versucht, die Ähnlichkeiten als die Verschiedenheiten herauszufinden, damit man sich dem Bundesverfassungsgericht anschließen konnte. Diese Tendenz hat freilich gewichtige Gründe, weshalb ich meine, daß sie auch in Zukunft nicht anders verlaufen wird.

Solch ein Grund sind vor allem die vergleichsweise geringen Kompetenzen der Landesverfassungsgerichte (günstiger steht es damit in Bayern und z.T. auch in Hessen). Die meisten Länder kennen keine Verfassungsbeschwerde, und auch sonst sind die Kompetenzen der Landesverfassungsgerichte insgesamt relativ gering. Ein Gericht, das wegen seiner wenigen Zuständigkeiten nur selten zusammentritt, wird schwerlich zu einer kontinuierlichen und in sich geschlossenen Rechtsprechung gelangen.

Mit den geringen Kompetenzen und dem damit auch relativ geringen politischen Gewicht der Landesverfassungsgerichte hängen Mängel ihrer Besetzung zusammen. Jedenfalls gilt das für Baden-Württemberg; in anderen Bundesländern mit anderen gesetzlichen Regelungen 
mag das anders sein. In unserem Bundesland jedenfalls kann man sich des Eindrucks nicht erwehren, als wenn die Besetzung für den Landtag als Kreationsorgan mitunter fast eine quantité négligeable sei. Der Gesichtspunkt fachlicher Befähigung ist mit den Jahren zunehmend hinter politische Erwägungen zurückgetreten. Als ich, 1958, erstmals in den Staatsgerichtshof gewählt wurde, wußte und fragte niemand, ob ich Mitglied oder Sympathisant einer Partei sei, und ggf. welcher. Inzwischen ist das anders geworden. Jetzt hat jede Partei ein bestimmtes „Kontingent“ an Richtersitzen, und Fragen der (tatsächlichen oder vermuteten) politischen „Richtung“ der zu Wählenden sind durchaus relevant geworden. Auch Prestigegesichtspunkte spielen eine Rolle für die Wahl. Wir haben eine Dreiteilung der Richterbank: 3 Berufsrichter, 3 weitere Juristen, 3 Nichtjuristen. Es scheint nun eine Prestigefrage für die Chefpräsidenten der Oberlandesgerichte und des Verwaltungsgerichtshofs zu sein, Mitglied des Staatsgerichtshofs zu werden. In meiner langen Amtszeit waren meist alle drei, mindestens aber 2 der Berufsrichterstellen so besetzt. Abgesehen davon, daß Zivil- oder Strafrichter nicht unbedingt eine besondere fachliche Nähe zum Verfassungsrecht aufweisen müssen, werden Chefpräsidenten wegen ihrer Beanspruchung im Hauptamt nicht immer die erforderliche Zeit zur intensiven Befassung mit einem Verfahren des Verfassungsgerichts aufbringen können, und als Berichterstatter fallen sie in aller Regel ganz aus. Kann man sich wundern, daß ein so besetztes Gericht nicht gerade den Ehrgeiz entwickelt, eine eigenständige Rechtsprechung zu entwickeln, wenn es die Möglichkeit sieht, sich an ein "Simile“ des Bundesverfassungsgerichts anzulehnen? Hinzu kommt der Zeitfaktor. Sind die Mehrzahl der Richter oder gar wie in Baden-Württemberg - alle Richter des Verfassungsgerichts neben- oder ehrenamtlich tätig, so ist es schon schwierig, einen für sämtliche (bei uns 9) Richter verfügbaren Verhandlungstag zu finden. Verhandlung, Beratung, Abstimmung und Absetzung des Urteils müssen also innerhalb eines oder allenfalls zweier zusammenhängender Tage durchgeführt werden; denn dieselben 9 Richter nochmals zu einem späteren Termin zusammenzubringen, erweist sich als kaum möglich. Die Zeit ist also jeweils äußerst knapp bemessen; die Tendenz, es sich möglichst einfach zu machen, ist daher nur zu verständlich. Dazu nur ein Beispiel: Der Bad.-Württ. SGH hatte anfangs die Antragsberechtigung politischer Parteien im Normenkontrollverfahren verneint. Als das Bundesverfassungsgericht diese Frage anders entschied, hat sich der StGH dem sofort angeschlossen. Es gab sicher manche Gründe für die Auffassung des Bundesverfassungsgerichts, es hätte aber sicher auch gewichtige Gründe für den StGH gegeben, seine Rechtsprechung aufrechtzuerhalten. Diese Frage ist aber im StGH kaum diskutiert worden. Warum sollte man sich den Kopf zerbrechen über eine Frage, 
die das Bundesverfassungsgericht, wenn auch zu einem anderen $\mathrm{Ge}$ setz, schon entschieden hatte? Auch in anderen Fällen bin ich nicht auf Gegenliebe gestoßen, wenn ich die Frage aufgeworfen habe, ob der StGH sich wirklich einer Ansicht des Bundesverfassungsgerichts anschließen müsse.

Ich will mit meinen Ausführungen die Bedeutung der Landesverfassungsgerichte keineswegs herabspielen. Es gibt, wie gesagt, Rechtsgebiete, auf denen sie wegen ihrer insoweit ausschließlichen Kompetenz ihre Bedeutung behalten werden. Aber im ganzen ist doch die Neigung der Landesverfassungsgerichte, sich an das Bundesverfassungsgericht anzulehnen, groß, und das wird m.E. auch so bleiben.

Vorsitzender: Vielen Dank, Herr Bachof. Ich habe eine Reihe von Wortmeldungen speziell zu den Fragen der Landesverfassungsgerichtsbarkeit. Ich möchte aber doch zunächst den Rednern, wie angekündigt, das Wort geben, die zu II. allgemein sprechen wollen. Deswegen gebe ich jetzt Herrn Bayer das Wort.

Bayer: Ich darf an das anknüpfen, was Herr Stern sagte. Ich habe, Herr Stern, aus threm Statement entnommen, Sie wollen sich bemühen, das Landesverfassungsrecht ein wenig mehr zur Geltung zu bringen. Auch ich würde mich gern gegen die Minimalisierung dieses Rechtsgebietes, vor allem zunächst durch Sie, Herr Isensee, wenden, und ich glaube darüber hinaus, daß eine wichtige sachliche Seite unseres Themas hier bisher zu kurz gekommen ist.

Ich schließe an das an, was Herr Fleiner gesagt hat. Herr Fleiner, Sie haben sozusagen horizontale bundesstaatliche Rechtsvergleichung betrieben. Ich meine, es gehört zum Thema auch ein wenig das, was man die vertikale bundesstaatliche Rechtsvergleichung nennen könnte. Herr Zacher hat heute morgen unsere japanischen Freunde und Kollegen besonders herzlich begrüßt. Ich darf diese Begrüßung noch einmal aufgreifen und sie mit der These 2.7 von Herrn Kollegen Schmid verknüpfen. Vor einigen Wochen ist im „Betrieb“, also in einer Zeitschrift, die in diesen Kreisen sicherlich nicht ganz regelmäßig gelesen wird, ein Aufsatz eines Experten der Steuerrechtsvergleichung, nämlich des Herrn Rädler, erschienen. Der Aufsatz beschäftigt sich mit dem Thema ,Steuererhebung und Steuerwirklichkeit in Japan“. Das Resümee dieses Aufsatzes: Wir müssen uns als Deutsche fragen, was können wir von den Japanern lernen? Dahinter die noch weitergehende Frage: Können wir denn überhaupt von den Japanern in bezug auf das Steuerrecht - etwas lernen? Dieses seinerseits wieder mit einem gewissen Zweifel versehen, nämlich dem Zweifel: Japan etwas ganz Fernes, Japan etwas ganz Fremdes, Japan etwas Exotisches, kurz: eine terra incognita. 
Die Referate heute morgen haben mich ein wenig an diesen Aufsatz von Herrn Rädler erinnert. Die Parallelen liegen, wie mir scheint, auf der Hand. Ich würde nämlich an einer Stelle wie dieser einmal Fragen wie diese formulieren wollen: Können wir Deutsche, bezogen auf unser Verfassungsrecht, überhaupt etwas von den Baden-Württembergern, von den Bayern, von den Burgenländern oder sogar - sicherlich noch etwas weitergehend - von den Aargauern oder den Appenzellern lernen? Können wir Deutsche, um die These, Herr Kollege Ipsen, vollends abzurunden, vielleicht sogar etwas von den Hamburgern lernen? Die Frage, hier aus der Sicht der Bundesrepublik Deutschland gestellt, ließe sich selbstverständlich genauso auch aus der Sicht der Österreicher und der Schweizer stellen, aber es ist nicht meine Aufgabe, das zu tun. Also: Können wir Deutsche überhaupt etwas vom Volk der Gliedstaaten lernen? Und wenn ja, dann was?

Zunächst zur ersten Frage: Ich bin in der Tat der Meinung, daß wir als deutsche Verfassungsjuristen von den Schwaben, den Bayern usw. immer wieder nur lernen können. Es bestätigt sich da bloß die alte Erfahrung, daß man aus zwei Dingen um so mehr lernen kann, um so verschiedener sie liegen. Und, die Dinge bei unserem Thema liegen, wie im Laufe des Tages nun schon mehrfach angeklungen ist, sehr verschieden; sie liegen deshalb sehr verschieden, weil es eben eine unterschiedliche Art von Staatlichkeit in einem Bund einerseits und in dessen Gliedern andererseits gibt.

Zur Verdeutlichung meiner ersten These nur dies: Herr Wacke hat vor etwa 40 Jahren einen Aufsatz geschrieben, in dem er sich um die Frage bemühte: Wie läßt sich das Steuerrecht rechtstechnisch am besten darstellen? Und darin steckte die Frage: Sollen wir dem Steuerrecht die Form von Verfassungsrecht geben? Und Herr Wacke hat uns damals gezeigt, daß wir als deutsche Verfassungsjuristen jedenfalls niemals ganz übersehen sollten, wie es diesbezüglich einmal in den schweizerischen Urkantonen ausgesehen hat. Folge ich Herrn Wacke, so ist dort ein Beispiel dafür gesetzt worden, daß das gesamte Steuerrecht eines Staates in dessen Verfassung zu finden sein kann: Oder: Verfassungsrecht „ferner" Gliedstaaten als Lehrstück für mögliches - oder unmögliches - deutsches Bundesverfassungsrecht.

Ich komme zu meiner zweiten Frage: Was können wir im einzelnen für die Verfassung des deutschen „Bundes“ aus dem Verfassungsrecht der Gliedstaaten entnehmen? Ich bin zunächst einmal der Ansicht, es läßt sich - Urkantone hin oder her - mit Hilfe der Gliedstaaten auch heute noch manches im Hinblick auf die Frage gewinnen, was in eine Verfassung hineingehört und was nicht. Die Weimarer Reichsverfassung zeichnete sich dadurch aus - und entschuldigen Sie bitte, daß ich schon wieder bei meinem Lieblingsthema bin -, die Weimarer Reichsverfassung zeichnete sich dadurch aus, daß sie einen Art. 134 
enthielt und dieser Artikel nahm das auf, was 140 Jahre früher der große Adam Smith uns in seinem „Wohlstand der Nation" vorgeführt hatte: Dank des Art. 134 gab es in Weimar verfassungsrechtlich umschriebene Besteuerungsgrundsätze. Im Grundgesetz ist das vergessen worden. Man hat sich hier ganz und gar auf das bundesstaatliche Steuerorganisationsrecht beschränkt, steuerliche Grundrechte und Grundpflichten kommen bekanntlich im Grundgesetz an keiner Stelle vor. Aber ich meine, es ist dieses ein Regelungsbereich, in dem man durchaus das Gefühl für eine Lücke empfinden kann, vor allem dann, lieber Herr Schmid, wenn man als Deutscher sein Geld in der Bundesrepublik und nicht in der Schweiz verdienen muß. Es könnte eine Lücke bestehen. Und wie schließen wir diese Lücke? Macht uns nicht allein das jeweilige Landesverfassungsrecht das Problem und dessen Lösung bewußt? Ich möchte nur festhalten: Es gibt gegenwärtig eine einzige deutsche Landesverfassung, nämlich die bayerische, die in ihrem Art. 123 ausdrücklich die Besteuerungsgrundsätze des alten Schotten wieder aufleben läßt. Und wir haben heute zusätzlich gehört - ich nehme an, es geht dies vor allem auch auf Anregungen von Herrn Häberle zurück -, wir haben heute auch gehört, daß es in der Schweiz die Vorschriften des kantonalen Verfassungsrechts gibt, die die alten Smith'schen Besteuerungsmaximen so gut wie selbstverständlich zu etwas für jeden Verbindlichen erklären. Ich komme noch einmal zu dem Schluß: Es ist nicht ganz unwichtig, um des Bundesverfassungsrechts willen auf das Landesverfassungsrecht zu schauen.

Es bliebe die Frage: Können wir in bezug auf das Wie einer Regelung aus dem gliedstaatlichen Verfassungsrecht etwas für die nächsthöhere Ebene, die des Bundes, ableiten? In der Tat, hier ist es wohl so, daß die Probleme sich potenzieren. Denn hier steht manches entgegen, was heute schon erwähnt worden ist: Das Homogenitätsgebot, der Art. 31 und vielleicht - wenn ich das nur am Rande noch einmal als Stichwort bringen darf - die Bundestreue. Diese Grundsätze stehen entgegen. Und trotzdem meine ich, wir sollten uns fragen: Können nicht landesverfassungsrechtlich Regeln entstehen, die irgendwann einmal für die Auslegung des Grundgesetzes oder der anderen hier diskutierten Bundesverfassungen von Bedeutung sein könnten? Es ist hier gelegentlich schon der Gedanke der allgemeinen Rechtsgrundsätze angeführt worden. Und es wäre in der Tat wohl so: Allgemeine Rechtsgrundsätze könnten sich auf der Ebene des Landesverfassungsrechts entwickeln und könnten dann danach rufen, auf irgendeine Weise sich auch auf der Ebene des Grundgesetzes usw. bemerkbar zu machen. In aller Regel steht dem sicher das Prinzip der kleinen Zahl entgegen, die allgemeinen Rechtsgrundsätze sind Grundsätze, die sich, wenn überhaupt, nur aus einer größeren Zahl von Verfassungen gewinnen lassen. Oder anders gewendet: Wenn 
hier von dem Beispiel Aussperrungsverbot nach der Hessischen Verfassung die Rede gewesen ist, so würde ich sagen: Wenn es dieses Aussperrungsverbot in einer größeren Zahl von Landesverfassungen geben würde, könnte daraus vielleicht doch etwas für den Umfang mit dem Problem: Aussperrung zulässig oder nicht? auf der Ebene des Bundes folgen. Meine These würde also lauten: Es gibt in mehrfacher Hinsicht eine Bedeutung des gliedstaatlichen Verfassungsrechts, und zwar aus deutscher Sicht eine solche für das deutsche Grundgesetz, aus österreichischer und schweizerischer aber, mit aller Vorsicht, sicher auch etwas entsprechendes für deren jeweilige Bundesverfassung. Danke.

Vorsitzender: Meine Herren, bevor ich Herrn Frowein das Wort gebe, noch kurz zum zeitlichen Ablauf: Wir sollten vielleicht gegen 17.30 Uhr zum Ende kommen. Vorher müssen die Referenten auch noch ausreichend Zeit haben für ihr Schlußwort. Es liegen ungefähr noch 12 Wortmeldungen vor. Man sollte daher nicht allzu ausführlich sprechen, sondern sich relativ kurz fassen. Nun Herr Frowein, bitte.

Frowein: Herr Vorsitzender, der präzise Sprachgebrauch des Vorstandes und der Referenten heute wird, wie ich denke, eines sicher erreicht haben: der schreckliche Doppelplural Länderverfassungen wird aus dem deutschen Staatsrecht verschwinden und man wird, wie der Vorstand dies mit Recht gesagt hat, von Landesverfassungen sprechen, genau wie die Schweizer nicht von Kantoneverfassungen, sondern von Kantonsverfassungen sprechen. Wie aber ist deren Bedeutung zu ermitteln? Doch wohl nur über den Versuch einer Bestandsaufnahme, den, wie ich meine, die Herren Funk und Schmid vorzüglich vorgeführt haben, der mir aber, wie ich gestehen muß, bei Graf Vitzthum ein wenig gefehlt hat. So reizvoll es ist, sich abstrakt um Bundesstaatlichkeit und Staatlichkeit überhaupt zu kümmern, so wenig, glaube ich, kann man der Fragestellung nach der Bedeutung der Landesverfassungen heute allein damit gerecht werden. Nun kann man sicherlich in einem kurzen Diskussionsbeitrag das hier nicht leisten, aber ich möchte doch $\mathrm{zu}$ den jetzt schon gegebenen Beispielen, und da will ich insbesondere auf Herrn Stern hinweisen, noch einige kleine Punkte nennen. Ich denke, im Regierungs- und Wahlsystem ist mehr drin, als deutlich geworden ist. Etwa die Regelungen, die in der Verfassung von Hamburg vor gar nicht so langer Zeit eingeführt worden sind, über die besondere Rolle der Opposition und, vielleicht noch wichtiger, Fragerecht und Antwortpflicht der Regierung, wozu das Bundesverfassungsgericht auf Bundesebene in Kürze wahrscheinlich Interessantes sagen wird. Ich meine schon, daß hier einiges an wirklichem Vergleich sinnvoll sein kann und uns auch zeigen kann, wo sich Dinge weiterentwickeln. 
Gewundert hat mich eigentlich, daß der doppelte Schulkampf, den wir erlebt haben in einer ganzen Reihe unserer Bundesländer auf Verfassungsebene, gar nicht recht zu Wort gekommen ist, wenn auch Herr Stern ihn dann angedeutet hat. Ich meine mit ,doppelt" folgendes: Der erste in Bayern, Baden-Württemberg und NordrheinWestfalen, diesen großen Bundesländern, vor sich gegangene war der um die Verfassungsänderung zum Vorrang der Gemeinschaftsschule (BVerfGE 41). Dieses war ein Vorgang von hoher Dramatik. Ich habe mich damit seinerzeit ein wenig näher beschäftigen müssen. Aber ich glaube, es ist wirklich ein Beispiel, daß wir in bestimmten Fällen Landesverfassungsrecht sehr bedeutsam in der politischen Auseinandersetzung finden. Der zweite war der, wo es um die Frage ging, wie weit man das Schulrecht durch den einfachen Gesetzgeber ändern kann und wie weit etwa Volksgesetzgebungsverfahren und verfassungsgerichtliche Verfahren in der Lage sind, hier zu bremsen. Dies ist m.E. ein Beispielsmaterial, das der Auswertung noch harrt.

Schließlich meine ich, daß, obwohl die Landesverfassungsgerichtsbarkeit jetzt mehrfach erwähnt worden ist, es doch gut wäre, sich zu fragen: Können wir nicht die Rechtsprechung der Landesverfassungsgerichte wirklich in ganz interessanter Weise vergleichen (natürlich mit dem von Herrn Bachof dargelegten unterschiedlichen Gewicht dieser Gerichte)? Aber wir haben eben, um das Schulrecht wieder aufzugreifen, einen weiten Bereich, wo Landesverfassungsgerichtsbarkeit bei uns eine echte Rolle gespielt hat. Oder die Frage: Wie hat sich eigentlich die radikale Rechtsprechungsänderung des Bayerischen Verfassungsgerichtshofes zu seiner Kompetenz, bezogen auf bundesrechtlich geregelte Entscheidungen, in der Praxis ausgewirkt? Ich habe diese Rechtsprechungsänderung seinerzeit, wie Sie alle, zur Kenntnis genommen. Mir ist aber nicht bekannt, was das eigentlich bedeutet hat in der dann nachfolgenden Rechtsprechung des Bayerischen Verfassungsgerichtshofes? Vielleicht könnte man als zwei Oberstichworte zur Diskussion dieser Fragen die bekannten Stichworte „Homogenisierung" einerseits, „Identitätsfindung des Landes" andererseits noch weiter verwenden und sich fragen, wie weit - und da stimme ich völlig mit einer Bemerkung von Graf Vitzthum in der Diskussion überein in der letzten Phase bestimmte Tendenzen zu stärkerer Identitätsbetonung auf Landesseite auch in der verfassungsrechtlichen Dimension ihre Rolle spielen. Daß es solche Wege von Homogenität zu stärkerer Identität auch ganz ungewollt geben kann, das merkt man ja, wenn man sich ansieht, wie heute der Terminus Freistaat Bayern von der Bevölkerung verstanden wird. Fragen Sie mal jemanden. Niemand wird Ihnen antworten, dies sei die deutsche Ubersetzung von Republik; homogen in der Weimarer Zeit für alle Staaten geltend - Freistaat Preußen usw. -, nur beibehalten von Bayern, aber heute nach 
allgemeinem Verständnis die Besonderheit Bayerns betonend. Danke schön.

Vorsitzender: Vielen Dank. Ich gebe nun Herrn Häberle das Wort.

Häberle: Herr Vorsitzender, verehrte Kollegen, erlauben Sie eine Fußnote zu dem Votum von Herrn Öhlinger, einen Zwischenruf zur Methodenfrage, schließlich drei Punkte, die ,zwischen“ die drei ersten Nummern Ihrer Gliederung fallen, Herr Vorsitzender. - Herr Öhlinger hat eindrucksvoll geschildert, daß das gastgebende Passau im 19. Jahrhundert gerne zu Österreich gestoßen wäre. Ich möchte im Gegenzug, aus Paritätsgründen diskret darauf hinweisen, daß Vorarlberg 1918 gerne der Schweizer Eidgenossenschaft beitreten wollte, diese wünschte aber keinen ,Zuwachs“. - Nun die methodische Zwischenbemerkung. Dank der Voten mehrerer Kollegen, darunter auch dank Herrn Grimm, ist ein wichtiges Zwischenergebnis erarbeitet worden: Wenn es ein Gebiet der Staatsrechtslehre gibt, in dem wir Fragen der politischen Kultur, des Sozio-Ökonomischen, der Verfassungspsychologie und symbolik in Kooperation mit den Politikwissenschaften kulturwissenschaftlich behandeln müssen, dann ist es die praxisorientierte Lehre vom Bundesstaat und in ihrem Rahmen das Nachdenken über die Bedeutung des gliedstaatlichen Verfassungsrechts, seiner Verständnisse und Selbstverständnisse. Graf Vitzthum hat soeben in einer Intervention den EG-Horizont nach dieser Seite der Kultur hin eindrucksvoll umrissen. -

Jetzt zu meinen drei Fragen, auch an die drei Referenten, Fragen, die in das Kraftfeld des Gliederungsschemas 1,2, und $3 \mathrm{zu}$ integrieren sind. Die erste Frage zielt auf die ,richtige" verfassungsstaatliche Bundesstaatstheorie. Welche Bundesstaatstheorie haben die Referenten ihrem eindrucksvollen Verständnis des gliedstaatlichen Verfassungsrechts zugrundegelegt? Mein Vorschlag zielt auf eine "gemischte" Bundesstaatstheorie, sie ist dem Typus Verfassungsstaat der heutigen Entwicklungsstufe angemessen. Zweitens geht es um den spezifischen, hohen Funktionswert gliedstaatlichen Verfassungsrechts heute, Maßgebliches hat bereits Herr Stern ausgeführt. Beflügelt vor allem durch die Schweiz nenne ich als Stichwort: „Werkstattcharakter" für den Typus Verfassungsstaat, Prozesse der Rezeption und Produktion über die Verfassunggeber, Verfassungsänderungen, Verfassungsinterpreten innerhalb des einzelnen Bundesstaates und grenzïberschreitend zwischen solchen. Drittens, hier im Einklang mit unserem Kollegen, dem „Bundestreue-Bayer", wie er sich nennen darf: Gibt es „gemeines" Recht im Bundesstaat, gemeinschweizerisches, gemeinösterreichisches, gemeindeutsches? Wie ist es methodisch und theoretisch zu begründen? Stichwort: ,innerbundesstaatliche Rechtsvergleichung“, Einheit 
der Rechtskultur, ein Lückenproblem? Wir stehen vor einer Fülle von Fragen. - Zunächst zum ersten Punkt, zur ,richtigen" verfassungsstaatlichen Bundesstaatstheorie: Wir Spätgeborenen, die wir als Zwerge und Epigonen ,auf den Schultern von Riesen“"stehen, vor allem auf denen von Weimar, verfügen ja über ein großes Theorieangebot dank intensiver Theorieentwicklungen: ich erinnere an das klassische Modell des ,dual federalisme", an die Lehre vom ,kooperativen Föderalismus" und an den ,unitarischen Bundesstaat" meines Lehrers Konrad Hesse (1962), auch an neuere Versuche zu einer kulturellen Bundesstaatstheorie (1980). Auf dem Hintergrund der drei Referate, die das höchst Individuelle der Entwicklungsphase ihres jeweiligen konkreten Bundesstaats so überzeugend herausgearbeitet haben, plädiere ich für eine ,gemischte" Bundesstaatstheorie. Ich darf das erläutern: Wir haben einmal die von Herrn Hesse für die 60er Jahre gültig beschriebenen unitarischen Tendenzen, sodann "Textspuren“ des kooperativen Föderalismus z.B. in Art. 91a und b GG; in der Entwicklung der $80 \mathrm{er}$ Jahre beobachten wir ein verstärktes Interesse an kultureller Differenzierung, an sozio-ökonomischem Trägerpluralismus und ihm entsprechender Dezentralität. Auf der Linie solcher Pluralität bewegte sich wohl auch Herrn Fleiners Votum zur weltweiten Bundesstaatsvergleichung bis Indien hin. Meines Erachtens läßt sich gar nicht abstrakt-generell ein für alle mal sagen, welches die „richtige“ Bundesstaatstheorie ist. Innerhalb des Typus „Verfassungsstaat" als Rahmen sind die Unterschiede allzu groß. In der Entwicklung des Typus Bundesstaats im Rahmen der westlichen Demokratien gibt es nur Teilelemente, die gemischt werden müssen. Das ist mein Modell der gemischten Bundesstaatstheorie. In ihr behalten entwicklungsgeschichtlich und je aktuell die einzelnen Theorien ihr relatives Recht: Bald treten das Unitarische i.S. vertikaler Gewaltenteilung, ebenso das Dualistische, bald die kooperative Politikverflechtung, bald mehr die sozio-kulturelle, auch wirtschaftliche Vielfalt als Elemente eines gemischten Ensembles hervor. Der verfassungsstaatliche Bundesstaat sollte sich nicht auf eine, „reine“ Theorie festlegen, auch zeigen sich Entwicklungsstufen und wechselnde Varianten und Akzentverschiebungen in Raum und Zeit, heute etwa eine gewisse Absetzbewegung weg vom Kooperativen, eine wachsende Mischung von mehreren Theorieelementen, die alle doch irgendwie präsent bleiben. Erst in den Koordinaten einer solchen - gemischten - Bundesstaatstheorie läßt sich die gegenwärtig wachsende Bedeutung des gliedstaatlichen Verfassungsrechts bestimmen. - Damit bin ich beim zweiten Punkt, dem Stichwort ,verfassungspolitischer Werkstattcharakter" der gliedstaatlichen Verfassungen im jeweiligen Bundesstaat, aber auch über diesen hinaus im Blick auf den Typus Verfassungsstaat, für Total- und Partialrevisio- 
nen von Bundes- und Länderverfassungen. Die Schweiz ist hier vorbildlich. Wir sehen hier intensive Vorgänge der Produktion und Rezeption, „Wellenbewegungen“, in Gestalt von Teil- und Totalrevisionen, und zwar nicht nur innerhalb der Schweiz, bei den Kantonen untereinander sowie (mit Herrn Schmid) Ausstrahlungen von diesen zum Bund hin, vielmehr sogar im Außenverhältnis, etwa im Austausch mit der Bundesrepublik Deutschland. So stammen manche Elemente des Schweizerischen Staatskirchenrechts, die neuerdings in einigen totalrevidierten Kantonsverfassungen rezipiert wurden, letztlich aus unserer Weimarer Reichsverfassung. So wurde die Verfassung Tirols kürzlich um eine eindrucksvolle Präambel angereichert, nach dem Vorbild Schweizer Urkantone bzw. deutscher Länderverfassungen. So gibt es Beispiele differenzierter Staatsaufgaben- und Grundrechtskata. loge, die zunächst in Einzelverfassungen erprobt wurden. So könnte der laufende Ausbau der Volksrechte in österreichischen Ländern eine Vorreiterrolle spielen, gibt es Zeichen für wachsendes Kulturverfassungsrecht in vielen Gliedstaaten Österreichs und der Schweiz. - Der dritte und letzte Punkt: Wie rechtfertigen wir ,gemeindeutsches“, „gemeineidgenössisches“, „gemeinösterreichisches“ Verfassungsrecht? Um mit diesem zu beginnen: In der österreichischen $\mathrm{Li}$ teratur kommt es, Herr Funk, noch nicht vor. Vor allem weil Österreichs Bundesstaat in der Entwicklung des gliedstaatlichen Verfassungsrechts etwas weiter zurückliegt. Vielleicht darf man insoweit von einem West-Ost-Gefälle „Schweiz/Bundesrepublik/Österreich“" sprechen. Das deutsche BVerfG, das Schweizer Bundesgericht und Teile der eidgenössischen Literatur arbeiten schon mit ,gemeinem Verfassungsrecht" als Kategorie. Wie begründen wir es? Innerhalb desselben Bundesstaates ist Rechtsvergleichung eine ganz spezifische ,interne“. Die Gliedstaaten sind unter sich mehr als bloß „Nachbarn“. Legitima. tion des gemeinen Verfassungsrechts ist die Einheit der Rechtskultur. Es geht um ein Erarbeiten ,allgemeiner Rechtsgrundsätze“, um das methodische Problem des Schließens von planwidrigen Lücken i.S. der Lückenlehren von Zitelmann bis Meier-Hayoz. Ich meine dessen Unterscheidung zwischen erlaubter richterlicher Rechtsfortbildung im „taktischen", nicht aber „strategischen" Bereich. Ich bin nach wie vor gegen die Schleswig-Holstein-Entscheidung des BVerfG im 27. Band. Art. 39 Abs. 2 GG ist im innerdeutschen Rechtsvergleich Ausdruck eines „allgemeinen Rechtsgedankens" des parlamentarischen Prinzips. Das BVerfG hat den Schleswig-Holsteinern damals „ewige“ Regierungen zugedacht. Freilich war 1969 wohl nicht absehbar, was sich heute in Sachen Barschel/Pfeiffer abspielen könnte. Die Einheit der Rechtskultur ist für das „Wachsen“ gemeinen Verfassungsrechts im Bundesstaat gewiß ein tragfähiger Gedanke, zumal auf dem Hintergrund einer kulturellen Bundesstaatstheorie. Graf Vitz- 
thum hat klangschön formuliert, gemeindeutsches Verfassungsrecht sei keine Novität, sondern eine Banalität. Doch dürfen wir keinesfalls mit Hilfe gemeinen Rechts die bundesstaatliche Vielfalt „,von oben" her vorschnell einebnen. Die Konsenshorizonte, in denen gemeines Verfassungsrecht „wird“ oder im Gegenteil abzulehnen ist, sind im Interesse der Vielfalt, auch Ungleichzeitigkeit des gliedstaatlichen Verfassungsrechts sorgfältig zu erschließen. Man darf nicht einfach parallele Regelungen quantifizieren und äußerlich addieren oder ,hochrechnen“. In der Schweiz hat man mit Recht vor einem bundesgerichtlichen „Imperialismus“ aus Lausanne zu Lasten der Kantone gewarnt. Es geht um einen Weg zwischen Scylla und Charybdis: Ja zu einem differenziert begründeten gemeindeutschen, gemeinschweizerischen bzw. gemeinösterreichischen Verfassungsrecht; aber auch Vorsicht: nicht zuviel Homogenisierung, sondern nach wie vor bundesstaatliche Vielfalt. Vielen Dank.

Vorsitzender: Vielen Dank, Herr Häberle. Herr Püttner, bitte.

Püttner: Meine Herren Kollegen, die Zeit ist fortgeschritten; wir müssen uns kürzer fassen. Aber gestatten Sie mir trotzdem noch den Versuch, einige Facetten dem Bild hinzuzufügen, das die Referenten und die vielen Vorredner gezeichnet haben. Es ist die Rede davon gewesen, daß wir Abschied nehmen müßten nicht nur von dem Stichwort Souveränität im Verhältnis Bund/Länder, sondern auch vom Begriff Staatlichkeit. Aber ich mache darauf aufmerksam, daß es dann keinen Unterschied mehr gibt im Rahmen von Dezentralisation zwischen Gemeinden und Bundesländern andererseits. Denn wenn nur die Eigenständigkeit in der Verwaltung und in der politischen Willensbildung betont wird (nach Art. 28 I 2 GG, gilt das gleiche Prinzip der Volksvertretung für Länder, Kreise und Gemeinden), dann ist kein Unterschied mehr zwischen Ländern und Kommunen. Dann ist alles einheitlich Ausdruck der Dezentralisation im Staat.

Es hinge also doch, so meine ich, einiges davon ab, ob wir gleichwohl behaupten könnten, die Länder hätten eine andere Qualität als die Gemeinden, und wenn sie nur Staaten honoris causa sind (vielleicht muß man eine solche Kategorie erfinden) oder ihr Prestige höher ist - das Wort ist bereits gefallen. Die Länder wollen ja hauptsächlich eine gewisse Dignität in Anspruch nehmen, die man mit dem Ausdruck Staatlichkeit belegen kann. Dies ist ein anspruchsvoller Titel, und diesen verleiht man den Untergliederungen, die man etwas herausheben will. Das hat schon eine gewisse Bedeutung, und zwar nicht nur rein juristische Bedeutung, sondern auch faktische Bedeutung. Wir beobachten heute in Staaten, die bisher zentralistisch waren, eine Regionalisierung - ich meine hier insbesondere Frankreich, 
Italien und Spanien -, und es wäre schon zu fragen, ob die Bundesstaatlichkeit deutschen Musters, Schweizer Musters, österreichischen Musters qualitativ etwas ganz anderes darstellt als die Regionenbildung in diesen Staaten.

Ein anderes Stichwort: Haben unsere Bundesländer oder hat das Landesverfassungsrecht tatsächlich so wenig Gewicht, wie es in einigen Beiträgen zum Ausdruck kam? Herr Stern hat schon darauf hingewiesen, daß ja doch die Verfassungsgerichte der Länder - und ich möchte mich jetzt auf diesen Punkt beschränken - in den letzten Jahren eigentlich doch viel Eigenständigkeit bewiesen haben, Eigenständigkeit in der Rechtsprechung und auch in der Auslegung der jeweiligen Landesverfassung. Wer die Gebietsreform miterlebte, wird in Erinnerung haben, daß die Verfassungsgerichte der Länder, soweit sie zuständig waren, eine explizite Rechtsprechung entwickelt haben, den Grundsatz der Systemgerechtigkeit geformt und auch Beiträge zur Theorie der Auslegung der Verfassung und der Gesetzesbegründung geliefert haben, was recht bedeutsam gewesen ist. Demgegenüber mußte man gleichzeitig erleben, daß man beim Bundesverfassungsgericht vom Dreierausschuß einen Zweizeiler bekam, in dem z.B. einem feinsinnig bemerkt wurde, daß eine Anhörung auch dann gegeben sei, wenn sich jemand Gehör verschafft habe (obwohl er nicht gehört worden war). Das war doch ein merkwürdiger Kontrast, der mich bestärkte in der Auffassung, daß in der Eigenstaatlichkeit der Länder - hier in puncto Verfassungsrechtsprechung - eine gewisse staatsrechtliche Reserve liegt, die vielleicht nicht immer und jedes Mal in den Vordergrund treten muß, die aber doch Bedeutung besitzt und bei Bedarf hervorgekehrt werden kann. Mir ist in dem letzten Schulrechtsstreit, den ich in Hessen noch zu führen hatte (immerhin drei Tage Verhandlung vor dem Staatsgerichtshof) um das Förderstufenabschlußgesetz, doch aufgefallen, daß der Staatsgerichtshof größten Wert darauf legte, eigenständig aus der Hessischen Verfassung zu deduzieren, und nur ganz am Rande bundesrechtliche Vorgaben, wie das Förderstufenurteil des Bundesverfassungsgerichts, hinzuzog. Ich glaube also schon, daß Ansätze erkennbar sind, die gegebenenfalls eine Grundlage geben für ein eigenständiges Landesverfassungsrecht und auch eine entsprechende Auswirkung in der Rechtsprechung. Aber ein Punkt würde mich im Blick vor allem auf die Schweiz noch interessieren: Gibt es - und ich habe aufmerksam vermerkt, daß weder Herr Schmid noch Herr Fleiner davon ein Wort gesprochen haben - einen Einfluß der Sprachenfrage, vielleicht auch sogar der Frage der ethnischen Minderheiten oder Mehrheiten in gewissen Staaten auf die Theorie vom Bundesstaat? Ist der Bundesstaat ein anderer, gewinnt er eine andere Qualität, wenn unterschiedliche Völkerschaften oder unterschiedliche Sprachen in einem Staat zusam- 
menleben oder ist das, wie ich aus dem Schweizer Referat entnehmen muß, völlig irrelevant für die Bundesstaatlichkeit? Ich wäre für einen ergänzenden Hinweis dankbar.

\section{Vorsitzender: Vielen Dank, Herr Püttner.}

Zippelius: In dem eindrucksvollen Referat von Graf Vitzthum scheint mir eine gewisse Spannung zu bestehen zwischen jenen Thesen, die das Grundgesetz und die Verfassungen der Länder als bloße Teilverfassungen bezeichnen und von einer Komplementarität der Gesamtstaatsverfassung und der Gliedstaatsverfassungen sprechen (2.1 und 2.5), und den anderen Thesen, nach denen die Verfassungsautonomie der Länder durch Art. 28 GG garantiert und beschränkt wird (3.4 und 4.2). Dies letzte legt nahe, nicht von einer bloßen Komplementarität, sondern von einem Rangverhältnis zwischen der Gesamtstaatsverfassung und den Gliedstaatsverfassungen $\mathrm{zu}$ sprechen und dann noch grundsätzlicher zu sagen: Die gesamtstaatliche Verfassung verteile überhaupt die gesamtstaatlichen Kompetenzen zwischen den Zentralorganen des Bundes und den Ländern. Wie auch immer die Entstehung eines Bundesstaates beginnt, im Ergebnis und verfassungssystematisch sind nicht nur die Kompetenzen der Zentralorgane des Bundes, sondern auch die Länderkompetenzen als konstituierte $\mathrm{Ge}$ walten zu begreifen. Der in der gesamtstaatlichen Verfassung begründete Dualismus von Entscheidungszentren, nämlich der Zentralorgane und der Länderorgane, unterscheidet den Bundesstaat vom Einheitsstaat, in welchem die Organsouveränität, Herr Püttner, eben ganz bei den Zentralorganen liegt. Dem von mir vorgetragenen Verfassungsverständnis entspricht es, daß die gesamtstaatliche Verfassung den Kompetenzendualismus näher ausgestaltet: durch die Verteilung der Gesetzgebungs-, der Verwaltungs- und der Rechtsprechungskompetenzen zwischen den Zentralorganen und den Ländern. Ich versuche also nicht, die Drei-Staaten-Theorie neu zu beleben, sondern spreche nur vom Gesamtstaat, den Kompetenzen der Zentralorgane und den Kompetenzen der Länder, wobei es dann eine zweitrangige Frage ist, ob man auch die (nichtsouveränen) Länder als „Staaten“ bezeichnen will oder nicht.

Vorsitzender: Vielen Dank, Herr Zippelius. Nun Herr SchmidtJortzig.

Schmidt-Jortzig: Verehrte Kollegen, unter Genehmigung des Vorsitzenden möchte ich noch einmal auf Punkt 1 unserer Diskussion zurückkommen und versuchen, mit den mir nur begrenzt gegebenen Fähigkeiten pathetischer Ausdruckskraft Ihnen einen Eindruck davon 
zu vermitteln, in welcher Weise, in welcher Dramatik eine Landesverfassung ganz konkret zum Zentrum von Problemringen und Lösungsvorschlägen in einer Krise, zum Richtpunkt von Identifikation der Bevölkerung werden kann. Das Land Schleswig-Holstein erlebt das derzeit. Herr Ipsen, Sie haben zu Recht darauf hingewiesen, daß wir uns mit manchen Aspekten unseres Themas bisher ziemlich steril und theoretisch beschäftigen. Was nun an dem schleswig-holsteinischen Beispiel viel mehr Leben und Anschaulichkeit gewinnen kann, ist die immer wieder beschworene normative, einigende Rolle, die Integrationsfunktion einer Landesverfassung. Das Konstitutionsgese $1 z$ in Schleswig-Holstein nimmt sich zwar - mein verehrter Vor-Vor-Vorgänger im Kieler Lehrstuhl, Herr Partsch, hat das hier deutlich gemacht - schon nominell in einer Weise zurück, die gemessen am üblichen Standard fast an Bescheidenheit, an Selbstverleugnung grenzt: als „Landessatzung“ bezeichnet sie sich. Und diese Konstitution würde, wenn man einige Kriterien von heute morgen anlegt, auch gar nicht als vollwertige, leistungsfähige Landesverfassung gelten können, denn sie hat bewußt auf jeden Grundrechtsteil verzichtet. Ein reines Organisationsstatut also liegt vor, welches seinen transitorischen Charakter auch noch in diesem ganz vorsichtigen Titel „Landessatzung" verdeutlicht. Aber dann kommt mit den nun offenliegenden, schweren Verdachtsmomenten gegen Ministerpräsident und Staatskanzlei eine Staatskrise größten Ausmaßes, völlig unvorhergesehen bricht sie herein. Und in dieser Situation beweist sich, wie jene Landessatzung die Kraft entfaltet, ruhender Pol und Richtungweiser, Integrationsbezug und Handlungsmaßstab für das Bundesland zu sein. Die öffentliche Diskussion in Schleswig-Holstein zur Frage Regierungsab. wahl, Untersuchungsausschuß oder Parlamentsauflösung dreht sich nicht um Lösungen, die vielleicht das Grundgesetz bereithielte, sondern geht allein darum, ob und wie die Landessatzung einen Ausweg bietet. Fast jeder Schleswig-Holsteiner von Lauenburg bis Flensburg, von Heide bis Lübeck weiß mittlerweile (nicht zuletzt auch durch den imposanten Einstieg aller Medien), daß sein Land ein eigenes Verfassungsgesetz hat, daß dieses rechtliche Fundament viel Besonderheiten gegenüber anderen Landesverfassungen sowie vor allen Dingen gegenüber dem Grundgesetz hat, und daß dahinter auch ganz bestimmte historische Erfahrungen und Vorstellungen stehen. Was ich damit versuchen möchte zu vermitteln, ist, wie dramatisch und unmittelbar eine Landesverfassung sich in einer Krisensituation, die das Land ganz persönlich, ganz existenziell, bis zur persönlichen Erschütterung der Bewohner erfaßt, als der entscheidende Integrationsfaktor bewährt und bestätigt. Mir jedenfalls, der ich das Los und die Spannung habe, dies hautnah mitzuerleben, drängt sich der Eindruck auf, so stark wie in dieser Krise jetzt war das Landesbewußtsein Schleswig-Holsteins, das 
Selbstgefuihl der Schleswig-Holsteiner seit langem nicht. Dies also, verehrte Kollegen, der bescheidene Versuch einer Entsterilisierung des Stichwortes ,Integrationsfunktion der Landesverfassung“.

Darf ich dann vielleicht noch zu einem anknüpfenden Aspekt eine kurze Frage stellen? Der Begleitaufsatz von Christian Pestalozza zu unserem heutigen Thema hat in einem - wie es sich für das kleine Land geziemt - ganz knappen und kleingedruckten Abschnitt Schleswig-Holstein attestiert, seine Verfassung behaupte unter den Bundesländern gegenüber dem Bund die größte Originalität und Selbständigkeit. Immerhin aus der Entfernung von Berlin: à la bonne heure! Dann jedoch weist er auf die Besonderheit hin, daß Schleswig-Holstein andererseits das einzige Bundesland, jedenfalls Flächenland sei, das kein eigenes Verfassungsgericht hat. Damit deutet sich eine These an, die mir auch in manchen Beiträgen heute durchzuscheinen schien und geradewegs auf das hinführt, was Herr Bachof vorhin ausführte. Ein eigenes Verfassungsgericht mag dazu neigen, die Strukturen im Lande denen im Gesamtstaat interpretatorisch anzugleichen, die zentralen Richter in Karlsruhe hingegen bemühen sich um die Eigenheiten der betreffenden Landesverfassung mit besonderer Sorgfalt. Auch in dem Referat von Herrn Schmid habe ich mir, nachdem dort mit großer Eindringlichkeit die Validität der Schweizer Kantone geschildert wurde, sogleich den Satz von der "weitgehenden Absence eigenständiger Verfassungsgerichtsbarkeit in den Kantonen" unterstrichen. Gibt es da tatsächlich eine Verbindungslinie zwischen fehlender Verfassungsgerichtsbarkeit und bestehender Verfassungsoriginalität, so daß man ironisch den Ländern raten müßte, ,schafft Eure Verfassungsgerichte $a b$ "? Ich meine, wenn dieser Blickwinkel wirklich Substanz haben sollte, müßte er schon über rein psychologische Bewertung und system. theoretische Mutmaßung hinausgelangen. Ich möchte mir deshalb herausnehmen, vielleicht Sie, Graf Vitzthum, da noch um eine Äußerung zu bitten. Danke sehr.

Vorsitzender: Vielen Dank, Herr Schmidt-Jortzig. Jetzt Herr Starck, bitte.

Starck: Ich erhalte erst zu vorgerückter Zeit das Wort und komme mir wie ein Zeitdieb vor, der den Berichterstattem ihre Schlußworte verkürzt. Die Probleme, die die Berichterstatter und die Diskutanten vor uns ausgebreitet haben, möchte ich gerne in ein Spannungsfeld einordnen, das bestimmt wird auf der einen Seite von Homogenitätsanforderungen, die die Bundesverfassungen je verschieden stellen, und auf der anderen Seite von der Verfassungsautonomie der Länder. Bei der Verfassungsautonomie muß man die rechtlichen Möglichkeiten von der tatsächlichen Inanspruchnahme unterscheiden. Uns ist eine 
Augenblicksaufnahme gezeichnet worden, die man dahin kennzeichnen kann, daß die Verfassungsautonomie in der Schweiz am weitesten geht, am engsten in Österreich geschnitten ist und die Bundesrepublik etwa in der Mitte liegt. Nun kann man die Verfassung und auch die tatsächliche Lage nach Faktoren abfragen. Welche Faktoren sprechen für die Homogenität und welche Faktoren sprechen mehr für die Verfassungsautonomie? Dazu ist schon viel gesagt worden, weshalb ich mich kurz fassen kann.

Zwei Beispiele sprechen dafür, daß man die Verfassungsautonomie mehr betonen muß. Das eine ist das Delegationsproblem, das noch nicht angesprochen worden ist. Die Länder sind nicht verpflichtet, eine dem Art. $80 \mathrm{GG}$ entsprechende Delegationsvorschrift in ihre Verfassung aufzunehmen oder entsprechende Verfassungsnormen über Delegation nach dem Maßstab des Art. 80 GG auszulegen. Es gibt viele Landesverfassungen, die entsprechend strenge Delegationsvorschriften haben, aber ich darf an die Diskussion in der Enquête-Kommission erinnern, die vorgeschlagen hat, die Delegationsvorschrift $\mathrm{zu}$ ändern, ohne damit in Konflikt mit der Rechtsstaatsgarantie zu kommen, die ein Faktor des Homogenitätserfordernisses in Art. 28 GG ist.

Den zweiten Punkt greife ich mit Rücksicht auf die Intervention von Herrn Häberle auf. Ich warne vor einem übermäßigen Gebrauch der Vorstellung vom gemeindeutschen Verfassungsrecht oder vom gemeindeutschen Landesverfassungsrecht. Hierin liegt meines Erachtens ein dogmatischer Hebel zur Entwertung des Landesverfassungsrechts. Da die Landesverfassungsgerichte, wie Herr Bachof richtig gesagt hat, eine Tendenz in diese Richtung zeigen, müßten wir eher gegensteuern. Wir haben im Gegensatz zu den Landesverfassungsrichtern die Zeit, uns mit diesen Fragen ausgiebig zu beschäftigen und zu vermitteln, was die Rechtslage nach der Landesverfassung des Landes $\mathrm{X}$ oder derjenigen des Landes $\mathrm{Y}$ ist.

Ein anderer Punkt, den ich leider nur kurz ansprechen kann, ist die Frage der Bedeutung der Grundrechte in den Landesverfassungen im Verhältnis zu den Grundrechten in der Bundesverfassung. Auf den ersten Blick sieht es so aus, als wenn die Grundrechte in den Landesverfassungen, sofern sie welche haben, ein starkes Stück Verfassungsautonomie der Länder darstellten. Das ist aber nur auf den ersten Blick richtig. Die Sozialrechte, die sich in der Bayerischen Verfassung finden, hat der Bayerische Verfassungsgerichtshof als Programm interpretiert und wohl auch interpretieren müssen. Was die kulturellen Rechte anbelangt, hat sich eigentlich nur auf dem Gebiete des Schulrechts etwas getan, im übrigen sind die kulturellen Rechte überaus zurückhaltend interpretiert worden. Die klassischen liberalen Rechte gibt es auch in den Landesverfassungen. Herr Stern hat auf den Datenschutz und die besondere Datenschutzvorsch rift in der nordrhein- 
westfälischen Verfassung hingewiesen. Aber dieses Landesgrundrecht ist nicht deshalb in Nordrhein-Westfalen bedeutungslos, weil es dort keine Verfassungsbeschwerde gibt, sondern weil das Bundesverfassungsgericht Art. 2 Abs. 1 GG mit Unterstützung der Lehre extensiv so interpretiert, daß alle möglichen Freiheiten der Bürger immer in den Grundrechtsschutz fallen. Das ist der wahre Grund für die auffällige Schwäche der klassischen Grundrechte in den Landesverfassungen und für die auffällige Homogenität der Länder. Ein weiterer Homogenitätsfaktor ist das Bundesverwaltungsgericht. Das Bundesverwaltungsgericht ist Revisionsgericht für Landesrecht geworden, indem es prüft, ob dieses mit den Grundrechten im Einklang steht oder grundrechtskonform ausgelegt worden ist. Ein letzter Gesichtspunkt zeigt uns, welch starke vereinheitlichende Kraft die Grundrechte haben. Das Bundesverfassungsgericht hat aus den Grundrechten eine Koordinationspflicht der Länder, also eine bestimmte Art und Weise der Aufgabenwahrnehmung hergeleitet. Ich erwähne nur die beiden Beispiele der Vergabe von Studienplätzen und die Pflicht, einen Rundfunkstaatsvertrag zu schließen.

Eine allerletzte und kurze Bemerkung zu dem empirischen Befund. Ich würde das, was Herr Grimm gesagt hat, unterstützen und brauche es nicht $\mathrm{zu}$ wiederholen. Ich möchte aber in bezug auf das Landesstaatsbewußtsein Bemerkungen machen, die in eine etwas andere Richtung gehen. In Kreisen der Bevölkerung wird durch die Eigenständigkeit des Landesrechts immer noch die Freizügigkeit als bedroht angesehen. Ferner dürfen wir die Selbstangleichung, die die Bundesländer dauernd vornehmen, nicht unterschätzen. Wenn man etwa die neueren Legislationen auf dem Gebiete der klassischen Materien des Landesverwaltungsrechts betrachtet, findet eine Selbstkoordination über Mustergesetze, über Staatsverträge und über Gesetzesauslegung statt. Und was machen wir Professoren in der Lehre? In Bayern werden Vorlesungen über deutsches und bayerisches Staatsrecht gehalten. In welchem anderen Land liest man eigentlich deutsches und Landesstaatsrecht? Mit dieser Frage möchte ich schließen.

Vorsitzender: Vielen Dank, Herr Starck. Wir sind mit der Zeit sehr knapp. Bitte, Herr Fiedler, ganz kurz.

Fiedler: Erlauben Sie nur einen kleinen ergänzenden Hinweis auf einen Bereich, der heute in der Diskussion keine Rolle gespielt hat, obwohl in den Referaten ab und zu ein Hinweis gegeben wurde, wenn ich einmal absehe von der reizvollen Schilderung unseres schweizerischen Kollegens bezüglich der besonderen Nähe der Schweiz zu finanziellen Fragen. Graf Vitzthum hat in seiner These 2.3 von der finanziellen Unabhängigkeit gesprochen. Ich habe mich die ganze Zeit über 
gefragt, auch bei dem Beitrag von Herrn Grimm, was das eigentlich für Gesichtspunkte sind. Sind sie etwa vorrechtlich, außerrechtlich? Sie haben mit Recht, meine ich, diesen Gesichtspunkt nicht nach außen verlegt, sondern es handelt sich um einen zentralen Punkt - auch verfassungsrechtlicher Art. Denn worauf stützt sich die Kreativität des Landesverfassungsrechts - es fiel hier das Stichwort „Individualität" -, wenn nicht auch auf diesen Gesichtspunkt? Ich meine, man sollte ihn mitberücksichtigen, wenn man daran geht, eine etwas schwebende Bundesstaatstheorie zu konstruieren. Sie darf eben nicht über diesen finanziellen Dingen schweben. Vielen Dank.

Vorsitzender: Vielen Dank. Bitte, Herr Wenger.

Wenger: Von dem, was ich zu den Ausführungen der Referenten bezüglich der finanziellen Ressourcen der Gliedstaaten sagen wollte, hat Herr Fiedler schon Wesentliches vorgebracht. Staatlichkeit, auch Staatlichkeit der Gliedstaaten, ist notwendig inhaltlichen Änderungen unterworfen, die sich aus dem jeweiligen Rollenverständnis des Staates in bezug auf die Gesellschaft ergeben. In einer Zeit, die dem Staat eine weitgehende Verantwortung für den Wirtschaftsablauf und für die Entwicklung der Wirtschaftsstruktur zuerkennt, in der über $40 \%$ des Volkseinkommens in und über die Staatskassen fließen, erscheint mir die Frage, welchen Anteil an den öffentlichen Mitteln die Verfassungsordnung des Bundes den Gliedstaaten überläßt, um mit diesem Anteil die ihnen zukommenden wirtschaftspolitischen Aktivitäten finanzieren zu können, von zentraler Bedeutung zu sein; ebenso wie die Gliedstaaten die Planung und Verwendung dieser Mittel regeln und wie sie dabei auf die Wirtschafts- und Finanzpolitik des Bundes Bedacht zu nehmen haben. Aus dieser Sicht hätte ich mir eine eingehendere Auseinandersetzung nicht nur mit der Finanzverfassung im traditionellen Sinn, sondern auch mit dem Art. 109 des GG für die Bundesrepublik Deutschland, dem Art. $31^{\text {quinquies }}$ Abs. 1 der schweizerischen Bundesverfassung und Art. 13 Abs. 2 des österreichischen B-VG erwartet. Die Frage, inwieweit die in diesen Bestimmungen normierte Koordinierungs- und Kooperationsverpflichtung für Bund und Gliedstaaten bei ihren konjunktursteuernden Aktivitäten im gliedstaatlichen Verfassungs- und Haushaltsrecht Niederschlag findet, bzw. welche Regelungsdefizite hier noch bestehen und worin solche begründet sein dürften, gehört ohne Zweifel zu den Problemen, die der moderne gliedstaatliche Verfassungsgesetzgeber und der zur Konkretisierung berufene einfache Gliedstaatsgesetzgeber zumindest teilweise noch zu lösen haben. Wenn beispielsweise Herr Funk in Punkt III/9 seiner Leitsätze darauf hingewiesen hat, daß in Österreich die Länder die weitreichenden Möglichkeiten einer Modernisierung ihres 
Haushalts(verfassungs-)rechts bisher kaum wahrgenommen haben, so ist das wohl euphemistisch ausgedruickt; realistisch gesehen haben die österreichischen Länder außer rudimentären Ansätzen derzeit überhaupt kein eigenes Haushaltsrecht. Mich und, wie ich annehme, nicht nur mich, hätte interessiert, wie die analoge Rechtslage in der Bundesrepublik und in der Schweiz ist und welche einschlägigen Probleme dort noch offen sind.

Vorsitzender: Vielen Dank, Herr Wenger. Bitte, Herr Rack.

Rack: Ich beziehe mich mit meinen Bemerkungen naturgemäß auf das Referat von Herrn Funk, nehme aber die Wortmeldung zum Anlaß, auch noch ein oder zwei Worte zu dem zu sagen, was Herr Öhlinger in meinen Augen etwas überzogen in seiner Wortmeldung zum Ausdruck gebracht hat. Ich gehe davon aus, daß Herr Funk nicht eine Stunde lang über ein Thema gesprochen hat, das es in Österreich nicht gibt. Und ich glaube, daß in diesem Zusammenhang zu konstatieren ist, $\mathrm{da} B$ es in Österreich neben anderen derartigen Gefällen auch ein Bundesstaatlichkeitsgefälle gibt, und zwar eines von Westen nach Osten; man sieht daher gerade dieses Thema außerhalb von Wien anders als ,in der Provinz".

$\mathrm{Zu}$ den Ausführungen von Herrn Funk kann ich mich relativ kurz halten, weil das, was er hier geschildert hat, ein Ambiente war, in dem ich mich durchaus wohlfühlen konnte. Was man meines Erachtens noch tun sollte, ist, den einen oder anderen Schattenstrich zu dem von Herrn Funk gezeichneten Bild anzufügen. Dazu meine ich, daß die Status-quo-Analyse, die Herr Funk gegeben hat, im Sinne des Föderalismus vielleicht sogar etwas optimistischer zu sehen ist, als er das ge$\tan$ hat; in bezug auf die Zukunftserwartungen bin ich hingegen etwas pessimistischer als er.

Lassen Sie mich das nur an einigen Beispielen kurz illustrieren. Herr Funk hat unter Punkt III beschrieben, was die Länder im Zusammenhang mit ihrer Landesverfassungsautonomie gemacht oder eben auch nicht gemacht haben. Diesbezüglich wäre insbesondere zum Thema Einrichtungen der unmittelbaren Demokratie nachzutragen, daß hier die bisher schlummernde Verfassungsphantasie der Länder in den letzten Jahren zu neuer Lebendigkeit erwacht ist, und die österreichischen Länder doch das eine oder andere Kind geboren haben, das wert ist, näher betrachtet zu werden und das auch wert sein könnte, in weiterer Folge Vorbild für den Bund zu sein. Ich denke dabei insbesondere an das von Herrn Funk en passant erwähnte Institut der Verwaltungsinitiative, wo die einschlägig Interessierten nunmehr in einer Art und Weise in eine Domäne des Staates eingreifen können, wie sie bisher nicht vorgesehen war. Auf der Ebene der Gemeinden, 
wo einzelne Landesverfassungen dieses Rechtsinstitut ebenfalls vorgesehen haben, beginnt sich auch das eine oder andere aktive Mitgestaltenwollen der Bürger schon ganz konkret abzuzeichnen.

$\mathrm{Zu}$ den Themen Parlamentarisches System, bzw. Kontrolle der Vollziehung, wäre darauf hinzuweisen, daß auch hier einige durchaus interessante neue Entwicklungen zu vermelden sind, die die Länder entwickelt haben - zum Teil aus dem Rechtsvergleich, zum Teil auch aus der unmittelbaren Situation ihrer Staatlichkeit heraus und wo sich damit auch hier eine gewisse Vorbildfunktion für das Verfassungsrecht des Bundes anbietet. Ich denke etwa an Einrichtungen, wie die Projektkontrolle, wo Kontrollverfahren geschaffen wurden und auch derzeit bereits gehandhabt werden, die es auf Bundesebene zumindest in dieser Form noch nicht gibt, von denen man aber annehmen kann, daß man sie auch dort schaffen müßte. Ein weiteres Beispiel, das man nachahmen sollte: Nach steirischem Verfassungsrecht ist es möglich, daß auch bereits zwei Prozent der Stimmbürger eine sog. Kontrollinitiative in Gang setzen, $d . h .$, daß die Rechnungskontrolle, nicht nur wie bisher von den Staatsorganen selbst, sondern etwa auch durch die Aktivbürgerschaft in Gang gesetzt werden kann.

Ausdrücklich zuzustimmen ist Herrn Funk, daß im Zusammenhang mit der Reform des parlamentarischen Systems die Minderheitenrechte noch nicht in der Weise ausgebaut worden sind, wie man das erwarten könnte. Ich weise aber zu diesem Kritikpunkt auf ein technisches Problem hin. Aus der Tatsache, daß in unseren Ländern ein gewisser Proporz der Großparteien in der Regierung nahezu die Regel ist, ergibt sich eine Situation, in der auf Länderebene Minderheitenrechte nun tatsächlich Rechte sehr kleiner Minderheiten sein würden. Hier stellt sich ganz ernsthaft die Frage, wo man etwa eine Untergrenze einsetzen kann, für das Verlangen nach einem Unterausschuß, wenn mit einem Drittelrecht noch überhaupt nichts erreicht ist.

$\mathrm{Zu}$ den Tendenzen künftiger Entwicklung meine ich, und ich habe das ja vorhin bereits angedeutet, daß man die Dinge im Zweifel eher skeptischer sehen sollte, als dies der Referent bereits getan hat. Ich vermute, daß zukünftige Einbußen der Kompetenzen der Länder nicht nur im Zusammenhang mit den von Herrn Funk genannten Umweltschutzagenden zu erwarten sind, sondern daß es zukünftige Eingriffe in die Verfassungsautonomie der Länder auch im Zusammenhang mit Fragen des Krisenmanagements bzw. der finanziellen Sanierung in unserem Staat geben wird. Hier zeichnet sich bereits ab, daß tiefergreifende Sanierungsversuche immer nur dann erfolgversprechend zu sein scheinen, wenn sie alles, was in diesem Staat auf Bundes-, Landes- und Gemeindeebene anfällt, über einen Leisten scheren. Ich denke dabei etwa an Diskussionen in Österreich zum Thema Pensionsreform, 
Steuerreform und dergleichen mehr. Da gibt es schon in der Vergangenheit eine Reihe von schlechten Beispielen, von denen ich glaube, daß sie Schule machen werden. Als man seinerzeit in Österreich über das Thema Vergabereform auf Bundesebene nachgedacht hat, ist man sehr rasch mit der Idee gekommen, in Form einer Verfassungsbestimmung dasselbe Regime auch gleich den Ländern aufzuoktroyieren.

Ein letztes Wort noch zu den künftigen Entwicklungen: Auch für Österreich wird sich, nicht im selben Maß wie das in der Bundesrepublik der Fall ist, aber eben auch, im Zusammenhang mit europäischen Integrationsentwicklungen für die Länder das Problem von Kompetenzverlusten ohne wirkliche Kompensation ergeben.

Vorsitzender: Ich darf noch einmal appellieren, möglichst doch etwas Selbstdisziplin zu üben, damit wir den Zeitrahmen einigermaßen einhalten können. Nun hat Herr Wahl das Wort.

Wahl: Die Hauptfrage ist nach meiner Meinung nach wie vor die: was lassen die gesamtstaatlichen Verfassungen für die Landesverfassungen übrig? Wir haben genug Stichworte gehört, die Anlaß zur Skepsis und zur Frage nach den Hypotheken geben, die auf den Landesverfassungen liegen. $\mathrm{Da}$ war vom Schatten des Bundes die Rede und davon, daß der Bund praktisch ein Gesetzgebungsmonopolist ist; angeführt wurden zu Recht die Dynamik des Sozialstaats, die einheitshervorbringende Kraft der Bundesgrundrechte, die ebenfalls einheitlich wirkende Parteienstaatlichkeit und dann die vielbesprochene Ausstrahlungswirkung des Bundesverfassungsgerichts auf die Landesverfassungsgerichtsbarkeit. In den Referaten ist als Maßstab für die Bewertung der Rolle der gliedstaatlichen Verfassung zurecht immer die Vorfrage nach den Funktionen der Verfassung gestellt worden. In aller Kürze möchte ich hier unterscheiden zwischen der Verfassung als rechtlicher Grundordnung und den politischen Funktionen der Verfassung.

Was sind im Kontext der Verfassung als rechtlicher Grundordnung und als Verfassungsgesetz die Substanz und die Funktion der Landesverfassungen? Hier ist wohl am ehesten sicherer Grund zugunsten der Landesverfassungen wenigstens in der Perspektive der Staatsrechtslehre. Wir haben die Stichworte vom Experimentalcharakter der Landesverfassungen und von ihrer möglichen Vorbildfunktion gehört; Herr Schmid hat auf das wechselseitige sich-Anregen von Bundesund Bundes- und Landesverfassungen bei der Ungleichzeitigkeit der Verfassungen hingewiesen. Erwähnt waren schon die Spielräume der Länder beim Regierungs- und Wahlsystem. Aber wie gewichtig ist dies alles im Verhältnis zu den erwähnten Hypotheken? Und dann ist in diesem Bereich natürlich als Bereich möglicher Substanz - für die 
Bundesrepublik unvermeidlich bei unserem gerichtsorientierten Denken - die Verfassungsgerichtsbarkeit in den Ländern ins Spiel gebracht worden, wobei wir jedoch gehört haben, daß es sie in Österreich nicht gibt, und daß sie in der Schweiz wenig Bedeutung hat, sicherlich auch deswegen, weil dort plebiszitäre Elemente eine ganz andere und wichtige Rolle spielen. Ich glaube aber doch, davor warnen zu sollen, daß wir das Heil für die Landesverfassungen nun fast ausschließlich in der Produktivität von Landesverfassungsgerichten sehen. Herr Schmid hat demgegenüber eine ganz ,einfache ${ }^{6}$ und dabei höchst wirkungsvolle Grundlage für die Bedeutung der Landesstaatlichkeit aufgezeigt, nämlich die ausgeprägte Steuerstaatlichkeit der Kantone. Wenn der größte Anteil der direkten Steuern bei den Kantonen anfällt, dann verbürgt eine solche Regelung in hohem Maß Sub. stanz für die Länder.

Zum zweiten Punkt, zu den politischen Funktionen der Verfassung: Wenn eine Verfassung Integration und Identifikation ermöglichen soll, dann stellt sich die Frage nach den Ansatzpunkten für die Integration, also im Hinblick auf die Integrationsfunktion der Landes. verfassung die Frage nach dem realen Substrat für Bundesstaatlichkeit. Aus meiner Sicht ist dabei die entscheidende Frage: wieviel Vielfalt ist eine Gesellschaft bereit hinzunehmen? In welchen Bereichen sind die Bürger bereit, unterschiedliche Regelungen in den einzelnen Bundesländern zu akzeptieren? In allen Fragen der Wirtschaft ist dies sicherlich nicht der Fall, in vielen anderen Bereichen auch nicht. Exemplarisch haben wir die Eigenständigkeit der Länder in Schulfragen dis. kutiert, sind dort aber sehr rasch auf ein gesellschaftliches Einheitlichkeitsbedürfnis, zumindest in der Bundesrepublik gestoßen, das zu dem rechtlich abgesichert ist. Ich darf in diesem Zusammenhang erinnern an die Entscheidung über die Schulformen im weltanschaulich-religiösen Sinne. Da hat das BVerfG im ersten Schritt sehr schön den Spielraum der Länderverfassungen aufgezeigt, um dann im zweiten entscheidenden Schritt die Grenzen aus Art. 4 I GG entgegenzusetzen. Im Ergebnis ist auch die Schule ein solcher Bereich, in dem die Gesellschaft nur sehr begrenzt Vielfalt hinzunehmen bereit ist.

Ein weiterer Bereich ist die Kultur; man möchte geradezu sagen, wenn irgendwo, dann herrscht im Bereich der Kultur die Vorstellung von Vielfalt und damit von Unterschiedlichkeit. Das wäre dann die Kulturstaatstheorie des Bundesstaates, die Herr Häberle eindrucksvoll dargelegt hat und bei der er heute dezent als bekannt vorausgesetzt hat, daß er ihr Autor ist. Aber auch beim Bereich der Kultur kommt man beim näheren Nachdenken in erhebliche Schwierigkeiten, wenn man danach fragt, wieviel binnennationaler Vielfalt wir uns hier leisten können, wenn wir einmal den Bereich der Folklore verlassen. Nehmen wir als Beispiel die Medienlandschaft: angesichts der weit- 
reichenden internationalen Verflechtungen geht es doch heute nicht mehr darum, ob es im privaten Fernsehen bayerische oder fränkische oder sonstige Medienkonzerne gibt, sondern allein noch darum, ob wir den amerikanischen Konzernen noch überhaupt ein oder zwei europäische Konzerne entgegensetzen können. Es begegnet uns also gerade im Kernbereich von Kultur, in dem man auf binnennationale Vielfalt setzen möchte, die ganz andere, weit über den nationalen Rahmen hinausweisende Linie, daß wir kulturelle Identität nur noch als europäische gegenüber der amerikanischen verteidigen zu können glauben.

Bleibt die abschließende Frage, was eigentlich den Bundesstaat und die Eigenständigkeit der Länder prägt. Herr Püttner hat auf eine interessante Entwicklung in anderen europäischen Ländern hingewiesen, auf den dortigen Regionalismus. Damit stellt sich aber die Frage, wie sich Bundesstaatlichkeit und Regionalismus zueinander verhalten. Sind die deutschen Länder vergleichbar mit den Regionen anderer europäischer Staaten? Was prägt das Landesbewußtsein in Bayern? Und wie verhält sich bayerisches Landesbewußtsein zum schwäbischen, fränkischen oder oberbayerischen Regionalbewußtsein? Die generelle Frage nach der Substanz, die die Landesverfassungen trägt, möchte ich gerne an die drei Referenten stellen, um auch Unterschiede in den einzelnen Ländern zu erfragen. Denn ich meine, was die Landesverfassungen trägt, sind sicherlich nicht die Normen allein.

Vorsitzender: Vielen Dank. - Bitte, Herr Lerche.

Lerche:Die letzte Bemerkung von Herrn Wahl gibt mir Anlaß, vielleicht noch eine punktuelle Frage aufzugreifen. Das Bundesverwaltungsgericht hat sich vor einiger Zeit mit der Ihnen vielleicht wieder inzwischen entrückten Konstellation zu befassen gehabt, daß sich der Bayerische Verfassungsgerichtshof in der Auslegung des Gleichheitssatzes einer etwas anderen Bahn bediente als die anderen Bundesländer. Das Bundesverwaltungsgericht hat die Wirkung dieser Entscheidung des Bayerischen Verfassungsgerichtshofes praktisch kassiert; also eine Kollision zwischen Landesverfassungsgerichtsbarkeit und Bundesverwaltungsgerichtsbarkeit, die, glaube ich, sehr viel tiefere Probleme in sich birgt, als es jetzt hier aus Zeitgründen dargelegt werden kann.

Vorsitzender: Vielen Dank, Herr Lerche. Nun Herr Ipsen.

J. Ipsen: Herr Vorsitzender, meine Damen und Herren, ich möchte - und der Beitrag von Herrn Lerche macht mir Mut hierzu - zum Abschluß Ihre Aufmerksamkeit noch einmal auf das Detailproblem der 
Landesverfassungsgerichtsbarkeit zurïcklenken. Gegen die von Herrn Bachof vorgetragene Realanalyse läßt sich natürlich nicht viel einwenden. Gleichwohl würde ich in Frage stellen, ob die Entwicklung in irgendeiner Weise zwangsläufig war. Ich würde mich eher der These von Herrn Stern verbunden fühlen, daß es vielfach am verfassungsprozessualen Instrumentarium zur Ausbildung von Verfassungsrecht fehlt. Auch die These von Herrn Püttner von einer Reservefunktion der Landesverfassungsgerichtsbarkeit würde ich für diskutabel halten. Wo immer der Zugang zum Verfassungsgericht verengt oder gar nicht erst eröffnet wird, bleibt das Verfassungsrecht unentfaltet, kann sich kein Verfassungsbewußtsein bilden und folgerichtig bezeugt die Rechtswissenschaft nur geringes Interesse. Mit einer gewissen Zuspitzung läßt sich behaupten, daß die Bedeutung des gliedstaatlichen Verfassungsrechts eine Funktion der gliedstaatlichen Verfassungsgerichtsbarkeit ist. Gestatten Sie mir, diesen Befund ganz kurz an einem Beispiel aus Niedersachsen zu illustrieren; ein Beispiel, in dem nach Herrn Bachofs Meinung an sich die Landesverfassungsgerichtsbarkeit ihre eigentliche Wirkung entfalten müßte. Die Gemeinden A, B und C werden durch ein Neugliederungsgesetz zusammengeschlossen und erhalten den $\mathrm{Na}$ men der Gemeinde A. Nach Wechsel der Regierung und neuen Mehrheitsverhältnissen im Landtag wird ein Neugliederungsänderungsgesetz beschlossen, daß der Gemeinde nunmehr den Namen der Gemeinde B gibt. Auf die Verfassungsbeschwerde der Gemeinde A wird das Änderungsgesetz vom Bundesverfassungsgericht für nichtig erklärt, weil es die Garantie der kommunalen Selbstverwaltung aus Art. 28 II verletze. Die niedersächsische Verfassung enthält in Art. 44 ebenfalls eine Garantie der kommunalen Selbstverwaltung, die sogar detaillierter ist als die des Grundgesetzes. Überdies wäre der Staatsgerichtshof schon wegen seiner Sachnähe fraglos besonders geeignet, eine derartige Streitigkeit zu entscheiden. Da das niedersäschsische Verfassungsprozeßrecht aber keine kommunale Verfassungsbeschwerde kennt, bleibt nur der Weg zum - im Gegensatz zum Staatsgerichtshof überlasteten - Bundesverfassungsgericht. Deshalb kommt es nicht zur Ausbildung von Landesverfassungsrecht, deshalb bleibt nur die Rezeption von Bundesverfassungsrecht. Unter solchen Umständen kann sich kein Landesverfassungsbewußtsein entfalten, und die Wissenschaft richtet ihren Blick wieder auf das Grundgesetz. Dieses Beispiel mag als Beleg dafür dienen, daß es nicht zuletzt an den Ländern selbst liegt, wenn das gliedstaatliche Verfassungsrecht in seiner Bedeutung hinter dem Bundesverfassungsrecht zurückbleibt. Nur vermag ich in dieser Entwicklung keine Zwangsläufigkeit zu erkennen, sondern glaube, daß sie jederzeit umkehrbar ist, und ich meine, Zeichen dafür zu entdecken, daß wir vor einer Renaissance auch des Landesverfassungsrechts stehen. Schönen Dank. 
Vorsitzender: Vielen Dank. Herr Zuleeg, bitte.

Zuleeg: Ich vertrete den Standpunkt, daß die Wirkungsreserven der Landesverfassungen in der Bundesrepublik Deutschland nicht vollständig ausgeschöpft sind. Aus Zeitgründen kann ich das nur exemplarisch belegen. Ich denke etwa an die Rechtsprechung des Bundesverfassungsgerichts zu den Schranken der Grundrechte aus der Verfassung, angewandt auf die Grundrechte ohne benannte Schranken. Ich glaube, man kann diese Rechtsprechung auch auf Grundrechte mit benannten Schranken ausdehnen. So sehr dieser Ansatz in meinen Augen zu begrüßen ist, hat das Bundesverfassungsgericht aber doch die Schwierigkeit, alle schützenswerten Rechtsgüter auf der Ebene des Grundgesetzes zu entdecken. Bezeichnend dafür ist, daß man sogar Kompetenzvorschriften strapaziert, um daraus schützenswerte Rechtsgüter abzuleiten. Ich bin nun nicht darauf versessen, Schranken der Grundrechte aufzuzeigen, ich meine aber, daß auf einigen Gebieten die Ausgeglichenheit fehlen würde, wenn solche Schranken nicht vorhanden wären, dort nämlich, wo die Zurückhaltung des Grundgesetzes groß ist. Das ist mit Rücksicht auf die Länderstaatlichkeit namentlich im Bereich der Kultur der Fall, aber auch in sozialen Angelegenheiten. Gewiß besteht das Bedenken, Herr Vitzthum, auf die Partikularität zurückzugreifen. Wir können nicht Bundesverfassungsrecht je nach dem Land verschieden ausgestalten. Aber ich meine, es bietet sich doch eine Möglichkeit, den Inhalt der Landesverfassungen in das Bundesverfassungsrecht einzuführen, wenn sich ein Anhaltspunkt im Grundgesetz findet. Und da denke ich in erster Linie an die Sozialstaatlichkeit. Das heißt also: Konkretisierung der Sozialstaatlichkeit aus Verfassungsbestandteilen der Länderverfassungen. Genauso könnte man bei kulturverfassungsrechtlichen Problemen vorgehen. Allerdings ist dafür eine so griffige Formel wie die der Sozialstaatlichkeit im Bundesrecht nicht enthalten. Da müßte man dann schon etwas mehr an Auslegung leisten und dazu etwa das Einfallstor des Art. 5 Abs. 3 GG benutzen. Darüber hinaus finde ich, daß die Landesverfassungen wie bei rechtsvergleichender Betrachtung herangezogen werden könnten, um Hinweise und Bausteine für die Fortentwicklung des Bundesverfassungsrechts zu gewinnen.

Vorsitzender: Vielen Dank, Herr Zuleeg. Herr Steiger, bitte.

Steiger: Herr Vorsitzender, Frau Kolleginnen, meine Herren Kollegen, ich möchte etwas zu Punkt 5 sagen. Graf Vitzthum hat mit Recht in seiner ersten These darauf hingewiesen, daß alles das, was zur Bedeutung des gliedstaatlichen Verfassungsrechts in der Bundesrepublik zu sagen ist, im Hinblick und im Zusammenhang der übernationa- 
len Einbettung der Bundesrepublik zu sehen ist. Ich bin einer von denen, die die Bedeutung des Landesverfassungsrechts in der Bundesrepublik heute höher einschätzen als manche von Ihnen, vielleicht auch als Graf Vitzthum selbst. Auch die zukünftige Bedeutung des Landesverfassungsrechts werte ich höher, als manche von Ihnen das tun. Herr Kisker und Herr Stein haben dankenswerterweise zu Punkt 2 schon einniges gesagt. Uberraschenderweise ist die eigentliche politische Diskussion um die Länder und ihr Verfassungsrecht von Europa her gekommen im Zusammenhang mit der Einheitlichen Europäischen Akte. Da bildeten sich so eigentümliche Koalitionen wie die zwischen Bayern und Nordrhein-Westfalen, zwischen Herrn Strauß und Herrn Rau. Da wurde auf einmal die Gefährdung der Länder in besonderer Weise deutlich, die faktisch die Bundesebene übersprang und auch zu überspringen geeignet ist. Andererseits hat aber meines Erachtens gerade, um auf die Frage des Landesbewußtseins einzugehen, diese Diskussion gezeigt, daß dieses vielleicht so unterentwickelt doch nicht ist. Ich glaube auch, daß in den $40 \mathrm{Jahren}$, die manche unserer Bundesländer inzwischen bestehen, andere sind natürlich viel älter, sich doch allmählich ein gewisses Landesbewußtsein entwickelt hat. Wenn man durch die deutschen Bundesländer reist, dann sieht man durchaus unterschiedliche Strukturen. Nun heißt es, daß selbst nationales Verfassungsrecht auf europäischer Ebene, wenn man die ganz radikale Position nimmt, eigentlich keine Rolle spiele, da es überlagert werde vom europäischen Recht. Diese Position ist inzwischen zurückgenommen. Bei den Grundrechten befinden wir uns, auch dank der Rechtsprechung des EuGH, im Prozeß der Entwicklung eines gemeineuropäischen Rechts der Grundrechte. Wenn man nun als ein dem Landesverfassungsrecht Geneigter versucht, gegen die Auszehrung des Landesverfassungsrechts durch europäischen Zugriff einen theoretischdogmatischen Damm zu bauen, dann fällt das nicht leicht und müßte eigentlich im einzelnen entwickelt werden.

Wegen der Kürze der Zeit mehr zu Protokoll erklärt, scheint mir doch folgendes zu bedenken zu sein: Die Europäischen Gemeinschaften sind in einem weiten Sinn, wie ich sehr viel früher einmal dargelegt habe, bündische Einheiten, wobei „bündisch“" sehr weit und nicht sehr präzise gedacht ist - ich war damals von Carl Schmitt ausgegangen. Wenn man diesen Ansatz wählt, gehört zu der bündischen Struktur die Garantie der Glieder. Das ist der eigentliche Sinn der Sache und kommt doch wohl auch in den Europäischen Gemeinschaften zum Ausdruck. Ich erinnere in dem Zusammenhang auch an das, was Herr Fleiner vorhin zur Demokratiegarantie gesagt hat. Je weiter sich nun das Tätigkeitsfeld der Europäischen Gemeinschaften über den wirtschaftlichen Bereich im engen Sinne hinaus ausdehnt, auch durch die Auswirkungen der Wahrnehmung der Kompetenzen auf diesem Be- 
reich in anderen Feldern, desto weiter zieht sich meines Erachtens auch eine Garantiepflicht der Europäischen Gemeinschaften für ihre Mitglieder und deren Bestand. Dies ist nicht nur im formalen Sinne zu verstehen, sondern auch in bezug auf die Substanz und die Funktion. Meines Erachtens bezieht sich daher diese Garantiepflicht auch auf den Bestand der Mitglieder, so wie die EG sie vorfinden, das heißt konkret für die Bundesrepublik in ihrer bundesstaatlichen Struktur mit den Ländern, mit deren Aufgaben, mit deren Funktionen und mit deren eigenem Verfassungsrecht. Mir scheint es nicht möglich zu sein, das von Herrn Doehring vorhin noch einmal in seiner klassischen Form dargelegte Prinzip der Abschottung der innerstaatlichen Struktur gegenüber dem Völkerrecht auch auf das Integrationsverfahren zu übertragen. Denn dieses Prinzip, das Herr Doehring vorhin ja nicht ohne Grund und sicherlich nicht zufällig am Haftungsproblem deutlich gemacht hat, ist ein Abgrenzungsprinzip gewesen, während wir es hier mit der Lösung von Kooperations- und Integrationsproblemen zu tun haben. Daher meine ich, daß die Europäischen Gemeinschaften auch für die Garantie des Bestandes der Länder verantwortlich sind. Zwei konkrete Dinge: Es ist mir durchaus verständlich, Graf Vitzthum, daß Sie sagen, die kulturellen Bestimmungen in den Landesverfassungen können nicht gegen eine öffnung des Medienmarktes als eine Art Abschottung provinzieller Kultur geltend gemacht werden, obwohl ich sonst sehr viel gegen diese Öffnung des Medienmarktes habe, das hängt aber mehr mit meinem Thema vom vergangenen Jahr zusammen. Aber ich meine, die Niederlassungsfreiheit mit den dazu vorausgesetzten Äquivalenzen berechtige die Europäischen Gemeinschaften nicht, ein Einheitsabitur in den Mitgliedstaaten einzuführen, sei es nach deutschem, sei es nach französischem, sei es nach irgendeinem anderen Muster, weii dabei Beschränkungen, Abgrenzungen eintreten würden, während es ja, wie Sie gesagt haben, um Öffnung, die Möglichkeit der Einbringung von Vielfalt gehen muß. Es scheint mir auch, von einer anderen Seite her, Ansätze zu geben, etwa aus der Systemtheorie, die die funktionale Bedeutung von Gliederungen und Untergliederungen deutlich gemacht hat und von dem heute noch nicht erwähnten, aber vielleicht doch nicht ohne weiteres in die Vergessenheit zu verstoßenden Prinzip der Subsidiarität. Das würde allerdings für den Bund bedeuten, und vielleicht wäre das für die Länder sogar hilfreich, daß er gezwungen ist, seinerseits seine Garantiefunktion gegenüber den Ländern und ihrer verfassungsmäßigen Möglichkeiten auch wieder stärker gegenüber den Europäischen Gemeinschaften wahrzunehmen. Dankeschön.

Vorsitzender: Vielen Dank, Herr Steiger. Herr Ipsen, ja, kurz und bündig. 
H. P. Ipsen: Was hier eben postuliert worden ist, ließe sich allenfalls begründen mit der Kehrseite des Art. 5 des EWG-Vertrages, wonach die Gemeinschaft Rücksicht auch auf die Mitgliedstaaten zu nehmen hat. Dabei ist folgendes zu bedenken: Die EG-Verfassung ist das, was ich eine Wandelverfassung genannt habe. Sie ist nach ihrer ganzen Anlage, ihrer Zweckbestimmung auf Dynamik ausgerichtet. Sie entwickelt sich weiter, und zwar auch außerhalb des im Vertrag vorgesehenen Vertragsänderungsverfahrens. Das hat sich z.B. im Ergebnis im „Mittlerweile-Beschluß“ (Herr Hilf nennt ihn „Solange II“) des Bundesverfassungsgerichts gezeigt - der Europäische Gerichtshof als gesetzlicher Richter i.S.d. Grundgesetzes. Diese Wandelverfassung überlagert sich den nationalen Verfassungen der Mitgliedstaaten, und die Bundesrepublik hat den Ländern gegenüber im Ratifikationsgesetz zur Einheitlichen europäischen Akte zugesichert, sich für die Interessen der Länder einzusetzen vorbehaltlich außenpolitischer oder integrationspolitischer Gründe. Die Kompetenz, diese Gründe zu qualifizieren, ist Sache des Bundes und nicht der Länder. Es ist kein Zweifel, daß darin ein Gefahrenmoment für die Länderzuständigkeiten gegeben ist, insbesondere auf dem Kulturgebiet (das ist heute morgen angeklungen in Ihrem Referat, Herr Vitzthum, in den Vorbereitungsaufsätzen der Zeitschriften leider in keinem Punkt berührt worden). Die Gemeinschaft operiert auf dem Gebiet der Kultur mit dem höchst verfänglichen Begriff der „Kulturwirtschaft", und damit werden Kulturerzeugnisse wie Bücher, Zeitschriften, Zeitungen Objekte der Wirtschaft - auch wenn sie nur aus Papier, wie Zeitungen, bestehen, die am nächsten Tag Altpapier sind. Infolgedessen aber sind sie „Wirtschaft" und werden von der Gemeinschaft vereinnahmt ohne Rücksicht darauf, daß nicht das Papier, sondern der geistige Gehalt die Essenz dieser Produkte darstellt. Das ist der Gefahrenpunkt, der für die Länderkompetenzen besteht im Bereich der Kultur.

Vorsitzender: Vielen Dank, Herr Ipsen. Herr Zeh, ich darf nun Sie bitten.

Zeh: Meine Herren, warum ich nicht auf meinen Beitrag ganz verzichte, hat nur den einen Grund: Ich möchte nicht, daß das Protokoll dieser Besprechung erscheint, ohne daß der Haupttäter für die mangelnde Relevanz des Länderverfassungsrechts - Entschuldigung: Landesverfassungsrechts - und die ausgehöhlte Staatlichkeit wenigstens namhaft gemacht ist. Der Hauptverantwortliche ist die Staatspraxis des kooperativen Föderalismus. Was ist von einer Verfassungsautonomie der Länder zu halten - was ja doch wohl heißen würde: Chance zur Verfassungsgesetzgebung durch die Landesparlamente -, wenn es diesen Landesparlamenten nicht einmal gelingt, das Agieren der je- 
weils eigenen Regierungen im Bundesrat, in den Verhandlungen über den Anteil an der Mehrwertsteuer, in den Fachministerkonferenzen und ihren etwa 1000 Subgremien usw. überhaupt ein wenig zu kontrollieren oder parlamentarisch anzubinden oder wenigstens sich Informationen darüber zu beschaffen? Selbst das gelingt ja nicht, und vor diesem Hintergrund sehe ich den Hauptpunkt. Ich denke, daß Staat im demokratischen Sinne erst dann gegeben ist, wenn man im Prinzip vollgültige Parlamente und Regierungen hat. Wenn aber diese Parlamente darauf verzichten, einige der wesentlichen Parlamentsfunktionen im parlamentarischen Regierungssystem wahrzunehmen, nämlich Regierungskontrolle und Vermittlung dessen, was geschieht, so daß das Landesvolk überhaupt weiß, wer für was zuständig und verantwortlich ist, wenn auf das verzichtet wird, dann kann es mit Länderstaatlichkeit und Relevanz von Landesverfassungsrecht freilich nicht allzu weit her sein. Natürlich wissen wir alle, warum das so ist. Parlamentarisches Regierungssystem heißt, daß die Landtagsmehrheit die Regierung aus sich selbst hervorbringt und folglich mit ihr politisch identisch und auf relative Konfliktfreiheit angewiesen ist. Trotzdem glaube ich, daß es die Möglichkeit gäbe, die - ich will mal sagen - latente Relevanz von Landesverfassungsrecht doch wieder etwas wirksamer zu machen, wenn man sich die Reparlamentisierung des kooperativen Föderalismus vornehmen würde. Dann könnte es plötzlich wieder ganz spannend werden, was die Bedeutung von Länderstaatlichkeit angeht. Schönen Dank.

Vorsitzender: Vielen Dank, Herr Zeh. Nun eine Frage von Herrn Dittmann an Graf Vitzthum.

Dittmann: Meine Frage an Graf Vitzthum bezieht sich auf seinen Leitsatz 7.1, in dem er die Bedeutung des Landesverfassungsrechts u.a. durch ein Verwertungsverbot zusätzlich relativiert und zwar durch ein Verwertungsverbot, wie es dort heißt, für die pointierten Werte der jeweiligen Landesverfassung. Ich verstehe dieses Verwertungsverbot, Graf Vitzthum, inhaltlich so, daß die Länder sowohl bei der Auslegung grundgesetzlicher Zweifelsfragen wie auch bei Abstimmungsprozessen im Rahmen des kooperativen Föderalismus Ihrer Ansicht nach gehindert sein sollen, sich gegenüber dem Bund bzw. den anderen Ländern auf Ihre landesverfassungsrechtlichen Besonderheiten, etwa im kulturellen oder schulischen Bereich, zu berufen. Sollten Sie, Graf Vitzthum, damit lediglich eine verfassungspolitische Empfehlung meinen, so bin ich damit einverstanden. Sollte Ihr Verwertungsverbot aber im Sinne einer rechtlichen Unzulässigkeit der Verwertung dieser landesverfassungsrechtlichen Besonderheiten zu verstehen sein, so würde mich interessieren, woraus Sie dieses Verwertungsverbot herleiten. 
Vorsitzender: Vielen Dank, Herr Dittmann. Meine Damen und Herren, die Rednerliste ist nicht nur abgeschlossen, sondern sie ist auch abgehakt. Und jetzt haben die Referenten die Last des Schlußwortes nach einer langen Debatte. Sie haben sich nicht zwischendurch geäuBert. Ich gebe zunächst Herrn Schmid das Wort.

Schlußwort Schmid: Ich möchte mit dem Feierlichsten einsteigen, mit der Frage, die Herr Wahl von unserer lieben alemannischen Schwesteruniversität Freiburg im Breisgau an uns gestellt hat, von wo her denn die Substanz des kantonalen Verfassungsrechts aus meiner Sicht noch kommen soll. Ich habe versucht, teilweise in meinem Referat eine Antwort zu geben. Wenn ich das nochmals ganz kurz zusammenfasse, glaube ich, daß es zwar einer Substanz bedarf an Autonomie der Kantone, an Handlungsspielräumen kantonaler Politikgestaltung, an einer entsprechenden finanziellen Ausstattung, daß aber kardinal dann wohl der Wille zur Behauptung kantonaler Eigenständigkeit und zur Behauptung einer föderalistischen Ordnung besteht, und der ist wohl nicht zu ersetzen. Wenn ich für einen Moment noch weitergehe, dann möchte ich mich auseinandersetzen mit etwas, was Herr Grimm in den Raum gestellt hat und was mich etwas beschäftigt hat, nämlich quasi die These, die Probleme seien im kleinen Raum nicht lösbar und im Grunde genommen sei die Entwicklung der Zeit so, daß der Wind dem Föderalismus oder auch der kantonalen Eigenständigkeit ins Gesicht bläst. Es ist hier dem gegenübergehalten worden, es funktioniere ja einigermaßen in der Schweiz. Ich glaube aber, wir haben sowohl wirtschaftliche als auch politische Verhältnisse, die das beweisen. Vielleicht ist es so, wie ein welscher Regierungsrat einmal festgehalten hat zum politischen System der Schweiz: C'est illogique, mais ça fonctionne. Aber es gibt vielleicht auch einige Gründe dafür. Ich versuche, sie anzutippen. Ich glaube, es gibt Abwägungsprozesse zwischen vielleicht weniger perfekten und weniger homogenen Lösungen, um Zugewinn an Partizipationsvorteilen zu erreichen. Es gibt auch Marktnischen kantonaler Politikgestaltung. Es braucht einfach genügend Phantasie, die aufzufinden. Und mir scheinen die Aufgabenkataloge der neueren Kantonsverfassungen durchaus aufzuzeigen, daß die Kantone dran sind, diese Marktnischen wieder zu entdecken und stärker zu besetzen. Dazu kann vielleicht auch beitragen, daß man bei gewissen Dingen, die man vereinheitlicht hat, nachher erhebliche andere Defizite wieder festgestellt hat, daß man Schwerfälligkeiten dafür eingetauscht hat. Also ich kann für unser Land nach wie vor eine gewisse Renaissance des Föderalismus feststellen, ohne daß ich stringent widerlegen könnte, daß Ihre Tendenz, die Sie namhaft gemacht haben, nicht auch im Zug der Zeit liegt. Es braucht vermutlich einiger Flexibilität und Phantasie, hier ein Optimum herauszudestillieren, in welchem die 
Kantone hier nach und vor Uberleben können. Zu Herrn Häberle: Sie haben mir die Gretchenfrage gestellt, welcher Bundesstaattheorie ich nachfolge oder anhänge. Nun, das ist eine schwierige Frage, weil ich, um George Bernard Shaw zu zitieren, zu jenen praktizierenden Katholiken gehöre, die im religiösen Bereich schon so viel glauben müssen, daß sie im säkularen Bereich nicht mehr viel glauben. - (Gelächter). Wenn ich mich unter dem entscheiden müßte, etwa in einem multiplechoice-Test, was Sie mir zur Verfügung angeboten haben, dann hätte ich noch am ehesten Neigung, der gemischten Theorie zu folgen (Gelächter), schon weil sie irgendwie verheißt, daß sie vielleicht doch keine Theorie ist. - (Gelächter). In Verlegenheit bringt mich auch die Aufforderung, über die Begründung für das gemeineidgenössische Recht nachzudenken, trotz der erwägenswerten Dinge, die Sie im Jahrbuch für öffentliches Recht darüber geschrieben haben. Ich gehöre eigentlich zu den Leuten, denen diese Kategorie nicht so gefällt, und bin eigentlich auch der Meinung, auch die Lückenfüllung im kantonalen Verfassungsrecht habe sich autochthon am kantonalen Staatsrecht auszurichten und nicht gemeineidgenössisches Staatsrecht beizuziehen. Ich könnte mir auch schlecht vorstellen, und vielleicht ist das ein gewagter Vergleich, aber zeigt die partikularistische Denkweise eines Baselstädters, ich könnte mir auch schlecht vorstellen, daß das Bundesgericht bei Lücken im schweizerischen Staatsrecht sich schlichtweg auf das Grundgesetz berufen würde und erklären würde, es liege da irgendeine weitere Rechtskategorie vor, die wir zur Lückenfüllung hinziehen. Ich bin genügend Partikularist, um mich beinahe so zu stören an dem, daß das Bundesgericht mir einfach mit einer Kategorie hantiert, die es eigentlich selbst generiert hat und die nach meiner Ǔberzeugung wenig einsichtig erscheint. Wenn ich also jetzt Ihnen Begründungen liefern müßte, so würde ich mein Ziel aus den Augen verlieren und der berühmten Metapher unterliegen, daß man, wenn man das Ziel aus den Augen verliert, dann wenigstens seine Anstrengungen verdoppelt. - (Gelächter). Zu Herrn Püttner: Sprachenfragen, ethnische Verschiedenheiten. Ich habe den Eindruck, daß diese für die Konzeptionen des kantonalen Verfassungsrechts keine Rolle gespielt haben. Es ist vielleicht sogar so, daß die ethnische Verschiedenheit der Schweiz, der „Willensnation Schweiz", in welcher ja eben sehr wenig direkt verbindendes, außer der historischen Entwicklung, zu verzeichnen ist, gerade den Zwang zur föderalistischen Ordnung und zu einer gewissen Staatlichkeit der Kantone einschließlich Verfassungsstaatlichkeit nach sich gezogen hat. Die Frage, wie weit unsere welschen Kollegen von der französischen Rechtskultur beeinflußt werden, ist eine interessante Frage. Soweit ich es sehe, ist das eher im Bereich des Verwaltungsrechts der Fall. Denn die staatsrechtliche Anlehnung an französische Kategorien mit dem doch immer stark vorhandenen Zentra- 
lismus ist wirklich kein verheißungsvolles Unterfangen für die welsche Minorität im schweizerischen Bundesstaat. Dort besteht, glaube ich, doch eine gewisse Immunität, so sehr man kulturell zum Teil nach Paris schaut. Politisch aber ist das aus der Minderheitsposition heraus keine verlockende Alternative. Zu Herrn Schmidt-Jortzig: Verfassungsgerichtsbarkeit in den Kantonen, das ist hauptsächlich ein Defizit in der Schweiz. Ich würde aber nicht so weit gehen und sagen, die Abschaffung der Verfassungsgerichtsbarkeit auf kantonaler Ebene stärke die Eigenständigkeit der Kantone. Es scheint mir hier ein pragmatischer Ansatz in der Schweiz Pate zu stehen für diese „Fehlanzeige" der Verfassungsgerichtsbarkeit auf kantonaler Ebene. Es fehlt irgendwie an der kritischen Masse für eine Verfassungsgerichtsbarkeit. Wenn Herr Bachof für das große Land Baden-Württemberg erklärt, daß das ein Problem gewesen sei, daß die Verfassungsrichter nur sporadisch zusammentreten und keine konsistente, kohärente Praxis entwickeln können, dann gilt das für die ungleich kleineren 26 Schweizer Kantone in noch erhöhterem Ausmaß. Also für mich ist das ein Problem kritischer Masse für die Kantone. Und zuletzt zu Herrn Wenger: Artikel $31^{\text {quinquies }}$ der Bundesverfassung sieht tatsächlich solche konjunkturpolitischen Ausgleichsfunktionen des Finanzgebarens vor und sieht tatsächlich vor, daß der Bund sie gegenüber den Kantonen in gewissen Grenzen in Anwendung bringen könnte. In der Staatspraxis hat das nie eine Rolle gespielt. Deficit spending ist aus Schweizer Sicht etwas, das geschehen kann, aber das man sicher nicht vorsätzlich unternimmt. Es gilt als so unanständige Unsolidität, daß man auch in Zeiten, als Keynes noch modern, darauf verzichtet hat.

Schlußwort Funk: Herr Grimm, Herr Ipsen und Herr Häberle haben eine stärkere Berücksichtigung des Realstatus der Länder, also des Föderalismus im sozio-politischen Sinne, und dabei insbesondere auch der tatsächlichen Rolle der politischen Parteien, moniert. Zweifellos sind diese Aspekte zu beachten. Ich glaube aber, daß ich für alle Referenten spreche, wenn ich sage, daß dies ohnehin geschehen ist zum Teil implizit, zum Teil auch in ausdrücklicher Form, jedenfalls aber in jenem Rahmen, in dem sich eine staatsrechtliche Betrachtungsweise zu bewegen hat. Den genannten Gesichtspunkten der sozio-politischen Realität kommt dabei erkenntnisleitende und systemstiftende Funktion zu. Im übrigen müssen wir uns aber der Grenzen staatsrechtlicher Fachkompetenz bewußt sein (was aber nicht als Ausklammerungsstrategie gemeint ist). Eine professionelle Analyse dieser Phänomene, deren Wichtigkeit außer Streit steht, liegt jenseits der Grenzen staatsrechtlicher Methodologie. 
Ich teile die Diagnose von Herrn Öhlinger. Für das Staatsrecht und die Verfassungspolitik stellt sich dabei die Frage nach einer Reform des Föderalismus in Österreich - eine Reform, die nur als Gesamtreform auf Bundesebene stattfinden könnte. Was die von Herrn Öhlinger angesprochenen Tendenzen eines neuen Föderalismus betrifft, die sich etwa in einem verstärkten Selbstbewußtsein der Länder und einem stärkeren Auftreten der Landeshauptmänner gegenüber dem Bund zeigen, so bin ich mir nicht sicher, ob es sich nicht dabei in Wahrheit nur um gewisse Umbruchserscheinungen in der Reichweite der Machtkompetenzen der politischen Parteien handelt, zusammenhängend mit einem Verfall der integrativen Kraft und Stabilität dieser Parteien auf Bundesebene. Wenn das der Fall ist, so bleibt abzuwarten, ob von daher ein nachhaltiger Effekt auf die Grundlagen des Föderalismus in Österreich zu erwarten ist.

Herr Öhlinger hat gemeint, ich hätte die Bedeutung des gliedstaatlichen Verfassungsrechts in Österreich in manchen Punkten eher zu optimistisch geschildert. Ob man diesem Bereich ,nahezu keine Bedeutung" beimißt oder aber doch „einige Bedeutung“ zugesteht, ist eine Frage von Akzenten. Es ist auch zu bedenken, daß hier noch lange nicht all das ausgeschöpft wurde, was darin an Möglichkeiten schlummert.

$\mathrm{Zu}$ den Fragen von Herrn Häberle, der von einer ,,gemischten Bundesstaatstheorie" gesprochen hat: Für Österreich hängt die Antwort auf die Frage nach der maßgebenden Bundesstaatstheorie mit dem Bundesstaatsstreit zusammen, dessen Ergebnis nach wie vor offen ist. Lange Zeit war die minimalistische Auffassung der Dezentralisationstheorie vorherrschend. Sie ist inzwischen unter massiven Beschuß geraten und es scheint, daß eine Kompromißvariante in Form der von Herrn Häberle angesprochenen gemischten Bundesstaatstheorie auch in Österreich im Begriff ist, sich durchzusetzen. Im übrigen ist anzumerken, daß es eine Art amtsoffizielle Bundesstaatstheorie auch in Österreich nicht gibt.

Herr Häberle hat weiters die Frage des Werkstattcharakters des Landesverfassungsrechts aufgeworfen: Sind die Länder sozusagen das "Westgalizien" für eine künftige Reform des Bundesverfassungsrechts? Manches deutet in diese Richtung. So wurde vor einigen Jahren versucht, durch eine Diskussion über die Aufnahme von Grundrechten in die Landesverfassungen stimulierend auf die seit langem festgefahrene Grundrechtsreform auf Bundesebene einzuwirken. Inzwischen dürfte auch hier einiges - wenn auch zögernd - in Bewegung geraten sein. Eine Werkstattfunktion des Verfassungsrechts der Länder könnte aber darüber hinaus auch in anderen Bereichen wirksam werden, etwa bei den plebiszitären Elementen oder beim Ausbau der Kontrollrechte parlamentarischer Minderheiten. 
Was den von Herrn Häberle angesprochenen Begriff des gemeinösterreichischen Verfassungsrechts angeht, so würde allein schon die Frage als solche bei einem Teil der österreichischen Kollegen Verwunderung hervorrufen, weil dieser Begriff keiner terminologischen Kategorie des österreichischen Verfassungs- und Staatsrechtsdenkens entspricht. Herr Häberle vermutet aber mit Recht, daß es so etwas auch in Österreich gibt (es ist nur bisher kaum noch gesehen worden). So ist in der neueren Rechtsprechung des Verfassungsgerichtshofes überraschend für denjenigen, der den Stil traditioneller Verfassungsrechtsprechung kennt - neuerdings öfters die Rede vom Grundsatz von Treu und Glauben, vom Verbot des Rechtsmißbrauchs, im besonderen auch vom Verbot mißbräuchlicher Kompetenzausübung und dergleichen. Mit solchen Argumentationsfiguren sind der Sache nach allgemeinrechtliche Prinzipien des österreichischen Verfassungsrechts angesprochen. In meinem Referat habe ich erwähnt, daß einige Landesverfassungen in ihrem proklamatorischen Teil ebenfalls darauf Bezug nehmen. Ob man dabei von ,gemeinösterreichischem Verfassungsrecht" sprechen will oder - wie Herr Starck meint - diese Terminologie besser vermeiden sollte, mag dahingestellt bleiben. Tatsache ist, daß das Phänomen als solches existiert.

Herr Schmidt-Jortzig vermutet, daß die Abschaffung der Verfassungsgerichtsbarkeit der Länder der Bedeutung des gliedstaatlichen Verfassungsrechts nützen könnte. Aus österreichischer Sicht möchte ich Zweifel anmelden. Bei uns hat jedenfalls der Verzicht auf eigene Verfassungsgerichte der Länder nicht geholfen.

Zur Frage von Herrn Wahl, was denn das Landesverfassungsrecht eigentlich trägt und wie es mit dem Landesverfassungsbewußtsein aussieht: In Österreich sind die Grundlagen eines solchen Verfassungsbewußtseins - sofern man von einem solchen überhaupt sprechen kann - wohl kaum im ethnischen Bereich zu suchen. Die österreichische Bundesstaatlichkeit hat keine ethnische Basis, mag auch bisweilen versucht werden, eine besondere Eigenart des steirischen, vorarlbergerischen, tirolerischen oder burgenländischen Menschen zu behaupten. An den in Österreich ansässigen ethnischen Minderheiten ist die bundesstaatliche Struktur völlig vorbeigegangen. Daran wird sich auch in absehbarer Zukunft (leider) nichts ändern. Eher schon könnte eine Grundlage für so etwas wie ein Verfassungsbewußtsein der Länder in einer weit verbreiteten, gegen Wien gerichteten Antipathie gesehen werden. Zum Teil gibt es auch - mit einem West-Ost-Gefälle - in den Ländern das Bewußtsein der historischen Einheit. Im übrigen müßte das Phänomen des Landesverfassungsbewußtseins mit den Mitteln vor allem der Sozialpsychologie und der Politikwissenschaft näher untersucht werden.

Zuletzt zu der von Herrn Rack für nicht ausreichend erachteten 
Berücksichtigung der Kontrollinstrumente, speziell im Bereich der Steiermärkischen Verfassung: Der Aufschwung dieser Einrichtungen verdient gewiß Beachtung, ihre besondere Entwicklung in einzelnen Ländern ändert jedoch nichts am Gesamtbefund. Ich versichere, daß all das in der schriftlichen Fassung meines Beitrages in den Fußnoten berücksichtigt wird. Die von Herrn Rack geäußerte Sorge, daß die Verfassungshoheit der Länder im Zuge der finanziellen Sanierung des Staates und im Zusammenhang mit der Hinwendung zu Europa weitere Einbußen erleiden könnte, teile ich nicht, denn ich frage mich, was den Ländern hier noch genommen werden könnte.

Wenn man sich die geradezu kriegerischen Töne vor Augen hält, die von Länderseite (besonders aus der Steiermark) aus Anlaß des Streites um die Stationierung von Luftraumüberwachungsflugzeugen zu vernehmen sind, und wenn man weiters davon ausgeht, daß das ius ad bellum ein Attribut gliedstaatlicher Staatsqualität ist, dann könnte man meinen, daß wir soeben Zeugen eines dramatischen Prozesses der Staatswerdung speziell eines österreichischen Bundeslandes sind.

Schlußwort Graf Vitzthum: Zunächst sage ich meinen Dank für die im besten Sinne belebenden, belehrenden und weiterführenden Diskussionsbeiträge. Ich bedanke mich sodann für die fünf Begleitaufsätze, die über mich während der Arbeit an dem Vortrag geradezu heruntergeprasselt sind. Es war - ich bin mehrfach danach gefragt worden - keineswegs so, daß sie mich behindert haben; im Gegenteil, sie waren eine Hilfe. Ich habe das Referat dann auch etwas im Sinne einer Komplementarität auf diesem Gebiet verstanden, indem ich Akzente u.a. bei Aspekten zu setzen gesucht habe, auf die die Begleitaufsätze zum Teil nicht eingegangen sind.

Nun in sechs Punkten kurze, fast überspitzte Antworten auf die verschiedenen Fragen und Stellungnahmen, stark zugespitzt aus Gründen der Zeit.

Erster Bereich: Staatlichkeit, Verfassungshoheit und - wie ich mehrfach in meinem Referat gesagt und in meinem Zwischenruf erneut gefordert habe - Realanalyse. Herr Doehring fragte nach dem Staatsbegriff des Völkerrechts. Der ist so ruiniert, daß wir von daher die Staatlichkeit der Gliedstaaten nicht konstruieren oder dekonstruieren können. Herr Partsch warf die Frage nach dem Landesbewußtsein auf: er bezweifelte sein Vorhandensein. Nun, wenn man sich an die fast panikartige Reaktion des verfassungsändernden Gesetzgebers erinnert, der nach den Abstimmungen in Schaumburg-Lippe und Oldenburg dem Art. 29 GG die Zähne ausschlug, kann man schwerlich bestreiten, daß eben doch offenbar noch einiges an irrationaler Substanz in den historischen Regionen, vielleicht auch in einigen älteren Ländern sowie nun bereits in manchen neueren Bundesländern vor- 
handen ist, und daß sich daraus ein Landesbewußtsein zunehmend Nahrung holt. Daß die Parteienstaatlichkeit oder das Parteienwesen bei uns unitarisch seien und deswegen eine lebenskräftige Landesstaatlichkeit in Zweifel zu ziehen sei - - auch diese These mag naheliegen; aber sie ist doch - selbst wenn sie empirisch belegbar wäre zumindest höchst gefährlich für die herrschende Bundesstaatslehre, die ja gerade im Föderalismus eine Möglichkeit zur Auflockerung des Parteienwesens sieht. Man muß zumindest diese beiden Dinge zusammen sehen. Der Theorie von der Komplementärwirkung des Bundesstaats für die Förderung des demokratischen Lebens - Herausbildung von Oppositionsführern, von regionalen Parteizentren usw. - würde zum Teil der Boden entzogen, wenn man die Parteienstaatlichkeit nicht doch als föderativ aufgelockerter ansieht, als in unserer Aussprache wiederholt vermutet wurde. Die Geschichte der Reform des Art. 29 GG scheint mir meine These von der in Wirklichkeit gar nicht so unitarischen Parteienlandschaft zu belegen. Es waren offenbar gerade nicht die „Großen Elefanten“ in Bonn, die die Entschärfung der Neugliederungsbestimmung betrieben haben, sondern die Landesparteifürsten; sie fürchteten, daß ihre Parteien - die austarierten Mehrheiten in ihren Ländern - gefährdet wären, wenn die Länder teilweise anders zugeschnitten würden. Verschiedentlich wurde in der Aussprache die finanzielle Unabhängigkeit der Länder angeschnitten - - in der Tat ein entscheidender Punkt. Zum diesbezüglichen realen Spielraum der Gliedstaaten ein erster Hinweis: Vor Beginn des Ersten Weltkrieges verfügte das Reich über $10 \%$ der Nettoeinnahmen, in der Weimarer Republik über $30 \%$; heute sind es bekanntlich $50 \%$. Herr Wenger fragte zu Recht, was denn aus Stabilitätsgesetz und mittelfristiger Finanzplanung geworden ist, die doch auch das Aktionsfeld der Länder beeinflussen (sollen). Nun, diese Instrumente sind in ihrer Wirkung weitgehend geschwächt worden. Die Gefahren jedenfalls, die hier aus der Sicht des parlamentarischen Regierens wegen der nur marginalen Einschaltung der Parlamente gesehen worden waren, haben sich als haltlos erwiesen, da das Instrumentarium - ein weiteres Beispiel für das Nichtfunktionieren großräumiger, umfassender Steuerungsversuche - sich als labil, als durchschlagsarm herausgestellt hat. Beim Bundesverfassungsgerichtsurteil zum Länderfinanzausgleich schließlich taucht plötzlich an versteckter Stelle "das bündische Prinzip", der Gedanke des Füreinandereinstehens, als ein Prinzip auf, das hier zu beachten sei. So unitarisch ist eben auch dieser Bereich offenbar nicht zu sehen. Verschiedentlich erwähnt wurde die Kultur als der vielleicht letzte Bereich, und dem sich die Länder stärker darstellen und definieren. Ich bin hier recht optimistisch. Denken sie etwa an einen Bereich, der gar nicht erwähnt wurde, den des Museumswesens. Wir erleben Versuche in vielen Bundesländern, Häuser der Geschichte 
einzurichten. Baden-Württemberg etwa macht ein derartiges Haus speziell für die baden-württembergische Geschichte, als Kontrast und Korrektur zu den nationalen Denk- und Gedenkstätten.

Zum zweiten Punkt, der Bundesstaatstheorie, die Herr Häberle mit Recht angefordert hat. Ich habe erwähnt, daß ich einen doppelten Funktionssinn des Bundesstaats - und das mag dann auf den Begriff der Mischung, des gemischten Systems, zielen - sehe: Sicherung eigener staatlicher Untergliederungen und gesamtstaatliche Mitwirkung. In beiden zusammengenommen sehe ich nach wie vor die Rechtfertigung und Lebensmöglichkeit für die Bundesländer, die von daher gesehen in der Tat - darauf hat insbesondere Herr Püttner hingewiesen - etwas qualitativ anderes sind als lediglich hochpotenzierte Selbstverwaltungskörperschaften. In jener Erhaltung der eigenen staatlichen Gliederung ist eben auch etwas Gefühlsmäßiges, etwas nicht rein rational Abdeckbares oder Ersetzbares enthalten; dies tritt neben die klassische Funktionsweise der Mitwirkung am Gesamtstaat und verstärkt insgesamt die Legitimation bundesstaatlicher Gliederung heute. Nun fragt Herr Zippelius - und dies ist die für mich schwierigste Frage -, ob es nicht doch so etwas wie ein Rangverhältnis zwischen Bundes- und Landesverfassung gibt, ob also der von Herrn Wahl eingeführte Begriff der Komplementarität nicht eine falsche Assoziation hervorruft. Nun, Sie haben selbst angedeutet, die Entstehungsgeschichte leitet hier zum Teil in eine andere Richtung. Das zweite Argument, das mich gegen ein Rangverhältnis sprechen läßt, ist, daß es sich hier in der Tat um ein Zusammenordnen von selbständigen politischen Einheiten handelt, wenn auch keine von ihnen die vollständige Wahrnehmung aller Staatsaufgaben in Anspruch nehmen kann. Im Fall der Kollision gibt es zwar eine „Uberordnung“ der Bundesverfassung, aber daraus folgt nicht, daß das prinzipielle Verhältnis der Komplementarität gegen ein solches der Vor- und Nachrangigkeit auszutauschen wäre. Bund und Länder sind natürlich, Herr Hesse hat das in seinem Lehrbuch in der berühmten langen Fußnote zu Beginn des Bundesstaatskapitels ja eingehend geschildert, intensiv aufeinander zu bezogen, und man kann darüber streiten, ob dieses Zusammenordnen und Einordnen nicht so umfassend ist, daß dann nur eben das Gesamtgebilde als Staat bezeichnet werden kann. Meines Erachtens sprechen aber die besseren Argumente dafür, daß auch die Glieder in unserem System Staatsqualität haben, jedenfalls in dem von mir als Glied-Staatlichkeit hervorgehobenen Sinne.

Drittens: die Landesverfassungsgerichtsbarkeit. Hier kann ich mich kurz fassen. Herr Schmidt-Jortzig, die über Art. 99 GG initiierte Rechtsprechung halte ich im Hinblick auf unser Spezialthema für uninteressant, jedenfalls was die Staatsqualität oder die Identität des Landes Schleswig-Holstein angeht. Da besteht hier kein Nexus zwi- 
schen dem speziellen Amt für Karlsruhe und der Bedeutung der Landessatzung für Kiel. Im übrigen ist kontrovers und eingehend diskutiert worden, ob die Landesverfassungsgerichtsbarkeit bedeutungsvoll ist oder nicht, und ob sie notwendigerweise anlehnungsbedürftig ist oder nicht. Ich glaube, ich kann mich darauf zurückziehen, daß Herr Bachof, der als Insider die größte Skepsis hinsichtlich der Bedeutung und Eigenständigkeit der Landesverfassungsgerichte geäußert hat, seinerseits der Autor einiger in jeder Hinsicht origineller Urteile des Staatsgerichtshofs Baden-Württemberg ist, so daß er sich im Grunde genommen selbst widerlegt durch seine Bescheidenheit. Die Frage: Landesverfassungsgerichtsbarkeit versus Bundesfachgerichtsbarkeit, Herr Lerche, hat sich mir so noch nicht gestellt. Vielen Dank für den Hinweis. Dem muß ich nachgehen.

Viertens: gemeindeutsches Verfassungsrecht. Ich hatte befürchtet, dies würde ein Schlüsselbegriff unserer Diskussion werden, so wie damals in Basel, als Sie, Herr Tomuschat, über den Verfassungsstaat im Geflecht der internationalen Beziehungen referierten und plötzlich die ganze Staatsrechtslehrervereinigung nur noch den Begriff soft law erörterte. Dazu ist es zu Recht heute nicht gekommen, wenn sich auch interessanterweise neben Herrn Häberle etwa die Herren Bayer und Zuleeg stärker für diese Kategorie erwärmt haben, und, wenn ich das richtig notiert habe, sich nur Herr Starck ähnlich dezidiert dagegen geäußert hat wie ich in meinem Referat. Meine Absicht und Aufgabe konnte hier lediglich sein, diese Kategorie zu nennen und auf die mit ihr verbundenen Probleme und Versuchungen hinzuweisen. Deswegen habe ich bewußt pointiert, ja kantig formuliert. Im Grunde genommen müßte man einsteigen in die gesamte juristische Methodenlehre, müßte weit über Laband und Gerber zurückgreifen, zumindest bis in die Mitte des 18. Jahrhunderts, und man müßte dann etwa wissenschaftsgeschichtlich die Ausstrahlungen in die Allgemeine Staatslehre und die Rechts- und Verfassungsgeschichte mitbehandeln. Im übrigen habe ich einen Spalt der Tür offen gelassen, indem ich von einer gewissen Interpretationsrelevanz dieser Kategorie sprach. Ich sehe diese übrigens, anders als Herr Zuleeg, in erster Linie bei der grammatikalischen Auslegung. Wenn Begriffe auf Landes- und Bundesebene gleich lauten, ist es naheliegend, daß sie auch das Gleiche meinen, selbst wenn man - entgegen Herrn Zippelius - nicht ein Rangverhältnis, nicht eine so eng geordnete normative Ordnung befürwortet. Ich habe dagegen große Bedenken, die Kategorie ,gemeindeutsches Verfassungsrecht" im Rahmen einer systematischen Interpretation anzuwenden. Die systematische Auslegung setzt ein Rechtssystem voraus, während sich der Bundesstaat gerade dadurch auszeichnet, daß er (auch) ein System der Widersprüche ist, ein System von Widersprüchen, die nicht durch eine solche Kategorie nun künstlich nivelliert werden dürfen. 
Die Selbstkoordination der Länder - der fünfte Diskussionsschwerpunkt, also praktisch das Gebäude des kooperativen Föderalismus, Herr Kisker und die Folgen - wurde vielfach angesprochen, und ich kann den Ergänzungen nur zustimmen. Allerdings möchte ich Herrn Zehs Beitrag dazu nutzen, meine These als bestätigt anzusehen, daß es den Landesparlamenten, die ja im wesentlichen die Landesverfassungen ändern könnten, mehr am politischen Wollen als am rechtlichen Dürfen mangelt. Die Landtage könnten ihre Position gegenüber dem Exekutivföderalismus stärken, sie tun es aber nicht. Sie verzichten auf entsprechende rechtliche Positionsverbesserungen, weil hier - da gebe ich Herrn Partsch Recht - die Parteienstaatlichkeit, die Parteisolidarität über das institutionelle Gefühl, das gewaltenteilende Wollen des Parlaments, siegt. Man muß fast die Landtage zum Jagen tragen in diesem Bereich der Kontrolle der gliedstaatlichen Kooperation.

Besonders dankbar war ich - und damit bin ich beim sechsten und letzten Punkt -, daß die Herren Wahl, Ipsen, Rack und Steiger - ich hoffe, ich habe keinen vergessen - meine EG-Thesen zumindest aufgegriffen, also anerkannt haben, wenn ich das richtig bewerte, daß die heutige Problematik des Gliedstaatsverfassungsrechts jedenfalls für die Bundesrepublik Deutschland auch in diesem dreistufigen - Hans Kelsen würde sagen: dreistöckigen - Bundesstaat zu sehen ist, und daß von dieser tendenziellen Dreistufigkeit die eine oder andere Relativierung gerade im Vergleich zu den föderativen Nachbarländern notwendig ist.

Mit einer letzten, in diesem Fall realanalytischen Bemerkung darf ich enden. Der Staat und gerade der Gesamtstaat ruht auf einer metajuristischen Basis. Dieses Fundament ist für die Bundesrepublik Deutschland, genauso wie es Nawiasky bereits für die Ära nach dem Ersten Weltkrieg konstatierte, der Wille zu nationaler Einheit. Dieses Bewußtsein und dieser Wunsch, weiterhin einer größeren Einheit zuzugehören, schließt nicht aus, daß man auch den kleineren Einheiten die gebührende Aufmerksamkeit widmet und auch ihren Rang und ihre Würde anerkennt. Danke.

Vorsitzender: Frau Kollegin, meine Herren, wir sind am Ende unserer Beratungen angelangt. Es steht dem Diskussionsleiter nicht an, irgendwelche Zensuren zu vergeben. Ich darf aber doch feststellen, daß wir eine fruchtbare und erhellende Debatte gehabt haben - mancher zunächst geäußerten Skepsis zum Trotz, wobei ich vor allem Herrn Meyer anschaue. Das Thema hat mich etwas an unsere Berliner Beratungen über Deutschland nach 30 Jahren Grundgesetz erinnert. Dort mußten wir auch in einer Zwitterstellung sowohl die Statur der Bundesrepublik wie auch die Verfassung der Bundesrepublik erörtern. Hier konnten wir die Probleme des Landesverfassungsrechts ebenso- 
wenig diskutieren, ohne uns gleichzeitig Gedanken zu machen über die Befindlichkeit der Gliedstaaten selbst.

Ich möchte nur zum Abschluß ganz herzlich den Referenten dan. ken, sowie allen Diskussionsteilnehmern. Zudem möchte ich mich bei allen denen entschuldigen, die frühzeitig eine Meldung abgegeben haben, die geglaubt haben, ich hätte ihre Meldung falsch eingeordnet, und die demzufolge zu dem Schluß gekommen sind, sie seien zu spät aufgerufen worden. Trotz des äußeren Anscheins ist aber einem jeden Recht widerfahren. Nur hat sich die Debatte in den Erstlingsabschnitten der vorgesehenen Gliederung verhakt und ausgedehnt. Wichtig scheint mir jedenfalls, daß sie bis zum Schluß substanzreich geblieben ist, wofür auch die Tatsache Zeugnis ablegt, daß der Saal trotz der späten Stunde noch gut gefüllt ist. 